\title{
Flujos masivos de población y seguridad. La crisis de personas refugiadas en el Mediterráneo $^{1}$
}

\section{Mass Influx of Displaced Persons and Security. The Refugee Crisis in the Mediterranean Sea}

\author{
Nuria Arenas-Hidalgo ${ }^{2}$ \\ Universidad de Huelva (España)
}

Recibido: 25-01-16

Aprobado: 26-02-16

\section{Resumen}

La intensificación de las corrientes migratorias hacia Europa, principalmente por vía marítima, como consecuencia de los conflictos de carácter económico, social y político en África y Medio Oriente supone un importante desafío para la Unión Europea en su objetivo de control de la inmigración irregular. Especialmente, el conflicto en Siria está provocando una crisis humanitaria sin precedentes y ya ha supuesto que el número de personas refugiadas en el mundo haya alcanzado cifras récord. La trágica y constante pérdida de vidas en el mar, así como las difíciles condiciones de acogida en los países ribereños del Mediterráneo, los más afectados por la crisis, ha provocado la adopción de algunas medidas insólitas en este campo. Por un lado, la puesta en marcha de una operación militar de gestión de crisis para la lucha contra el tráfico de personas (EUNAVFOR MED Sophia), con el beneplácito de la Resolución 2240 (2015) del Consejo de Seguridad de Naciones Unidas, y que plantea importantes interrogantes en torno a la militarización de un problema esencialmente humanitario; el adecuado cumplimiento del principio de no

\footnotetext{
${ }^{1}$ El presente estudio se enmarca dentro del proyecto de investigación: "Las Respuestas del Derecho Internacional y Europeo a los Nuevos Riesgos y Amenazas Contra la Seguridad Humana" (RASEGUR), Plan Nacional de I+D+I (Ref.: DER2015-65906-P) y de la Red de Excelencia sobre "Los actuales desafíos del Derecho Internacional", del Plan Estatal de Investigación Científica y Técnica y de Innovación 2013-2016 (DER15-69273-RED).

2 (nuria@uhu.es) Profesora Titular de Derecho Internacional Público y Relaciones Internacionales. Centro de Investigación en Migraciones, Universidad de Huelva.
} 
devolución de personas en peligro de persecución o daño grave; y la ausencia de vías de acceso seguras a Europa que es la auténtica piedra de toque del sistema europeo común de asilo. La segunda medida insólita ha sido la adopción de dos Decisiones para la reubicación de personas desde Grecia e Italia al resto de Estados miembros de la Unión. Se trata de una medida que incide en la obligada solidaridad entre los socios comunitarios y que pone en evidencia que no todos los Estados miembros pueden garantizar similares cuotas de seguridad a las personas solicitantes de protección, principio estructural de la Política europea de asilo, y demuestra la falta de equidad en el reparto de la responsabilidad en materia de refugio entre Estados que comparten un espacio de convivencia que pretende ser un modelo para el mundo.

Palabras-clave: crisis en el Mediterráneo; crisis de personas refugiadas sirias; operación EUNAVFOR MED Sophia; Resolución del Consejo de Seguridad 2240 (2015); Decisiones de reubicación desde Grecia e Italia; seguridad de las personas refugiadas; vías de acceso seguro a la protección; principio de non refoulement; solidaridad internacional; reparto de la responsabilidad en materia de personas refugiadas.

\section{Abstract}

The growing tide of migrants heading to Europe fleeing economic, social and political conflicts in Africa and the Middle East represents a huge challenge for the European Union as it struggles to control illegal immigration. The civil war in Syria in particular has unleashed an unprecedented humanitarian crisis, which is largely responsible for the record number of refugees worldwide at this time. The constant tragic loss of life at sea, as well as the strain put on the frontline countries of the European Mediterranean coast that receive the refugees, have led to the adoption of exceptional measures to cope with the migrant influx. A military crisis management operation has been set up to counter people trafficking (EUNAVFOR MED Sophia), with the blessing of the United Nations Security Council Resolution 2240 (2015). This throws up some important questions: the militarization of an essentially humanitarian problem; proper compliance with the principle of non-refoulement of persons in danger of persecution or serious harm; the absence of a safe access to Europe that is the real cornerstone of the common European asylum system. The second unusual measure is the adoption of two Decisions to relocate people from Greece and Italy to the rest of the EU member states. This is based on the idea of compulsory solidarity among members, but which reveals that not all EU states can guarantee similar levels of safety for those persons who seek protection, which is a core principle of the European policy on asylum. It also highlights the unfair distribution of refugees 
among States, who share a space for harmonious coexistence whose aim is to be a model for the rest of the world.

Key-words: Mediterranean refugee crisis; Syrian refugees; EUNAVFOR MED Sophia EU military operation; United Nation Security Council Resolution 2240 (2015); Council Decision to relocate from Italy and Greece; refugees security; Legal entry channels for persons in need of protection; principle of non refoulement; international solidarity; responsibility sharing for refugees.

\section{Introducción}

Existen hoy 60 millones de personas forzosamente desplazadas en el mundo. Se trata de la cifra más alta que se conoce desde que se dispone de registro de las mismas 3 . Si bien el $86 \%$ de estas personas se hayan en países en vías de desarrollo - para los cuales, las vicisitudes aparejadas a estos flujos ya se han convertido en una circunstancia endémica ${ }^{4}$-, en Europa, el estallido del conflicto en Siria, junto con el recrudecimiento de aquellos que se suceden en Iraq, Afganistán, Eritrea o Somalia, ha aumentado hasta tal punto el número de desplazamientos que podemos afirmar que nos hallamos ante la crisis humanitaria más importante de nuestra era $^{5}$.

El conflicto en Siria - especialmente cruel con la población civil- ya se ha cobrado más de 250.000 víctimas y 7 millones de personas desplazadas internas $^{6}$. Las Partes en conflicto han cometido crímenes de guerra, graves violaciones de derechos humanos e inclusive actos que constituyen crímenes contra la humanidad, con una impunidad generalizada ${ }^{7}$, por lo que los 4 millones de personas que han conseguido escapar del país no parece que tuvieran otra

${ }^{3}$ UNHCR. Mid-YearTrends 2015. 18 de diciembre de 2015.

El montante global incluye tanto a las personas desplazadas internas, como a las solicitantes de asilo y refugiadas. Según estas cifras, una de cada 120 personas en el mundo ha sido forzada a abandonar su residencia habitual. El número de personas refugiadas en el mundo ha superado los 20 millones por primera vez desde 1992.

${ }^{4}$ ACNUR. Mundo en Guerra. Tendencias Globales. Desplazamiento Forzado en 2014. 18 de junio de 2015, p. 2.

5 El Alto Comisionado de Naciones Unidas para los Refugiados, António Guterres, ha venido calificando así la crisis siria desde 2013. Vid. Inter alia: http://www.unhcr.org/515d8a789.html

${ }^{6}$ Internal Displacement Monitoring Centre: 7,6 millones a julio de 2015. http://www.internaldisplacement.org/middle-east-and-north-africa/syria/

${ }^{7}$ ACNUR. Consideraciones de protección internacional con respecto a las personas que huyen de la República Árabe Siria. Actualización III. Octubre de 2014, para. 8, p. 5.

Según el último informe del Secretario General de Naciones Unidas sobre la aplicación de las Resoluciones del Consejo de Seguridad 2139 (2014), 2165 (2014) y 2191 (2014), de 11 de diciembre de 2015, "el desarrollo de las hostilidades por todas las partes en el conflicto siguió caracterizándose por el desprecio generalizado al derecho internacional humanitario y a la obligación de todas las partes de proteger a la población civil". S/2015/962, 11.12.2015, para. 3 in fine.

Araucaria. Revista Iberoamericana de Filosofia, Política y Humanidades, año 18, n 36. Segundo semestre de 2016. Pp. 339-372. ISSN 1575-6823 e-ISSN 2340-2199 doi: 10.12795/araucaria.2016.i36.15 
opción que huir. Lo han hecho, sobre todo, a países vecinos. Así, Turquía $(1,7)$ y Líbano $(1,8)$ acogen 10 veces más refugiados que toda Europa que sólo ha tramitado hasta el momento 813.599 solicitudes de asilo ${ }^{8}$. Desbordada la capacidad de acogida de estos países, comienzan a incrementarse las llegadas a Europa. El volumen de llegadas es tan alto -en una semana pueden arribar hasta 23.000 personas a las costas griegas- que para los países que se encuentran en las fronteras del Mediterráneo está resultando imposible gestionar adecuadamente estos flujos. En 2014 se registraron 626.710 solicitudes de protección internacional lo que supuso un incremento respecto al año anterior de 195.000. Sin embargo, en la primera mitad de 2015 han aumentado en un $86 \%$, según Eurostat ${ }^{9}$. La auténtica tragedia, no obstante, se encuentra en las miles de personas muertas y desaparecidas en el intento de llegar a Europa. Se calcula que en 2014 perdieron la vida 3.072 personas y en 2015 la Organización Internacional de las Migraciones (OIM) ha aumentado la cifra hasta las $3.771^{10}$. Prácticamente a diario se nos informa de estas muertes que ya han convertido al Mediterráneo en la ruta más mortífera del mundo. Muchas de las personas que desembarcan en Grecia o Italia, ante las deficientes condiciones de acogida y las ínfimas posibilidades de obtener protección, inician la ruta de los Balcanes a través de Yugoslavia y Serbia hasta Hungría. Con independencia de que en ese viaje suelen producirse devoluciones contrarias al Derecho Internacional e incluso tratos inhumanos o degradantes ${ }^{11}$, en Europa, el cierre de fronteras, la construcción de vallas y los mensajes racistas y xenófobos nos han trasladado a los peores años de nuestra historia ${ }^{12}$. Esta crisis nos ha mostrado con claridad las lagunas del modelo de protección internacional diseñado para Europa y, en último extremo, las deficiencias de la solidaridad del proyecto común.

Piénsese que todas las personas que llegan a Europa, independientemente de la causa que les ha empujado a huir de sus países, ya sea la pobreza, los desastres naturales, la persecución o los conflictos armados, tienen derecho a que se les trate con dignidad y en estricto cumplimiento de las obligaciones en materia de derechos humanos. No obstante, se ha de reconocer que los flujos de

\footnotetext{
${ }^{8}$ Entre abril de 2011 y noviembre de 2015: UNHCR. Sirian Regional Refugee Response: http:// data.unhcr.org/syrianrefugees/asylum.php

${ }^{9}$ Unión Europea. Eurostat. Asylum Quaterly Report, 2015.

${ }^{10}$ Respecto a las cifras de 2014, véase: OIM. Fatal Journeys-Tracking Lives Lost during Migration, 2014, p. 20. En relación con las de 2015, puede consultarse la siguiente fuente online: OIM. Missing Migrants Project: http://missingmigrants.iom.int/

${ }_{11}$ Naciones Unidas. Comité contra la Tortura. Concluding Observations on the third periodic report of the Former Yugoslav Republic of Macedonia.CAT/C/MKD/CO/3, 05.06.2015.

12 En el verano de 2015, Hungría construyó una valla de 175 kilómetros y 4 metros de altura a lo largo de su frontera con Serbia para frenar la inmigración. El 27 de agosto, la policía húngara llegó a utilizar gases lacrimógenos frente a varios centenares de inmigrantes en un centro de recepción a cuatro kilómetros de la frontera con Serbia. El Gobierno de Orbán asegura que "los inmigrantes, principalmente musulmanes, suponen una amenaza a la prosperidad de Europa, a la seguridad y a los valores cristianos". Diario El País: Miles de refugiados quedan varados en las fronteras balcánicas, 20.10.2015.
} 
personas que intentan cruzar las fronteras marítimas tienen un carácter "mixto", es decir, aglutinan tanto a personas que huyen de la miseria e intentan mejorar su calidad de vida y que para entrar en Europa han de cumplir con las condiciones estipuladas en la normativa común; así como personas que huyen de peligros que la comunidad internacional ha considerado que alcanzan tal gravedad que merecen la concesión de protección internacional. Las personas solicitantes de asilo, refugiadas y aquellas que huyen de la pena de muerte, la tortura y los conflictos armados tienen reconocidas garantías adicionales que los Estados están obligados a dar efectivo cumplimiento. Los Estados miembros de la Unión Europea que se enfrentan a esta crisis sin precedentes han de asegurarse, por tanto, que sus políticas y actividades relacionadas con la gestión de las fronteras, incluidas las medidas de interceptación o rescate, tengan en cuenta esa composición mixta y procuren el efectivo cumplimiento de las obligaciones que dimanan del "Sistema Europeo Común de Asilo", especialmente diseñado para la concesión de protección internacional ${ }^{13}$.

En virtud de este sistema normativo ${ }^{14}$, la protección internacional

${ }^{13}$ El Código de Fronteras Schengen que establece normas aplicables al control fronterizo de las personas que crucen las fronteras exteriores de los Estados miembros de la UE, debe realizarse de forma que se respete plenamente la dignidad humana, y, en virtud del artículo 13, se dispone que la denegación de entrada de nacionales de terceros Estados que no cumplan con las condiciones de entrada no será obstáculo para la aplicación de las disposiciones especiales en materia de asilo y protección internacional. Reglamento (CE) n $n^{\circ}$ 562/2006 del Parlamento Europeo y del Consejo de 15 de marzo de 2006 por el que se establece un Código comunitario de normas para el cruce de personas por las fronteras (Código de fronteras Schengen), DO L 105, 13.04.2006.

${ }^{14}$ Las normas de Derecho Derivado básicas del Sistema Europeo Común de Asilo son:

Reglamento (UE) núm. 604/2013, del Parlamento Europeo y el Consejo, de 26 de junio de 2013, por el que se establecen criterios y mecanismos de determinación del Estado miembro responsable del examen de una solicitud de protección internacional presentada en uno de los Estados miembros por un nacional de un tercer país o un apátrida, DO L, 180/31, 29.06. 2013. En lo sucesivo, Reglamento Dublín III.

Reglamento (UE) núm. 603/2013, del Parlamento Europeo y el Consejo, de 26 de junio de 2013, relativo a la creación del sistema "Eurodac" para la comparación de las impresiones dactilares para la aplicación efectiva del Reglamento (UE) núm. 604/2013, por el que se establecen los criterios y mecanismos de determinación del Estado miembro responsable del examen de una solicitud de protección internacional presentada en uno de los Estados miembros por un nacional de un tercer país o un apátrida, y a las solicitudes de comparación con los datos de Eurodac presentadas por los servicios de seguridad de los Estados miembros y Europol a efectos de aplicación de la ley, y por el que se modifica el Reglamento (UE) no 1077/2011, por el que se crea una Agencia europea para la gestión operativa de sistemas informáticos de gran magnitud en el espacio de libertad, seguridad y justicia, DO L, 180/1, 29.06. 2013. En lo sucesivo, Reglamento EURODAC.

Directiva 2001/55/CE del Consejo, de 20 de julio de 2001, relativa a las normas mínimas para la concesión de protección temporal en caso de afluencia masiva de personas desplazadas y a medidas de fomento de un esfuerzo equitativo entre los Estados miembros para acoger a dichas personas y asumir las consecuencias de su acogida. DO L, 212, 07.08.2001.

Directiva 2011/95/UE, del Parlamento Europeo y el Consejo, de 13 de diciembre de 2011, por la que se establecen normas relativas a los requisitos para el reconocimiento de nacionales de terceros países o apátridas como beneficiarios de protección internacional, a un estatuto uniforme para los refugiados o para las personas con derecho a protección subsidiaria y al contenido de la protección concedida, DO L, 337/9, 20.12. 2011. En adelante, Directiva 2011/95.

Directiva 2013/32/UE, del Parlamento Europeo y el Consejo, de 26 de junio de 2013, sobre procedimientos comunes para la concesión o la retirada de la protección internacional, DO L, 180/60, 29.06. 2013. En adelante, Directiva 2013/32.

Araucaria. Revista Iberoamericana de Filosofía, Política y Humanidades, año 18, n 36. Segundo semestre de 2016. Pp. 339-372. ISSN 1575-6823 e-ISSN 2340-2199 doi: 10.12795/araucaria.2016.i36.15 
incluye el "estatuto de persona refugiada" y el de "beneficiario de protección subsidiaria". El estatuto de refugiado/a se concede a las personas que tienen fundados temores de persecución por las 5 razones tasadas (raza, religión, nacionalidad, pertenencia a determinado grupo social u opiniones políticas) que ya habían sido consensuadas en la que se conoce como piedra angular del Derecho Internacional de las Personas Refugiadas, esta es, la Convención de Ginebra sobre el Estatuto de los Refugiados de $1951^{15}$. El estatuto de beneficiario de protección subsidiaria se otorgará a aquellas personas que no reúnen los requisitos para ser refugiados/as, pero respecto de las cuales se den motivos fundados para creer que, si regresase a su país de origen, se enfrentarían a un riesgo real de sufrir alguno de los tres daños graves tasados (condena a pena de muerte o su ejecución; tortura o penas o tratos inhumanos o degradantes; o la violencia indiscriminada en situación de conflicto armado internacional o interno $)^{16}$. Estas personas tienen derecho ante todo a no ser desembarcadas, forzadas a entrar, conducidas o entregadas a ningún país donde exista riesgo de verse sometida a estos daños (principio de no devolución). Y también tienen derecho a solicitar protección internacional, pero para ello han debido cruzar una frontera internacional y estar presentes en territorio europeo(incluida la frontera, en las aguas territoriales o en las zonas de tránsito de un Estado miembro $)^{17}$. No es de extrañar, pues, que a falta de otras vías de acceso seguro

Directiva 2013/33/UE, del Parlamento Europeo y el Consejo, de 26 de junio de 2013, por la que se aprueban normas para la acogida de los solicitantes de protección internacional, DO L, 180/96, 29.06.2013. En lo sucesivo, Directiva 2013/33.

La política común de la Unión en materia de asilo, inmigración, visados y controles en las fronteras exteriores se basa en el título V (Espacio de libertad, seguridad y justicia) del Tratado de Funcionamiento de la Unión Europea (TFUE). En virtud de los Protocolos 21 y 22 de los Tratados, el Reino Unido, Irlanda y Dinamarca no participan en la adopción por el Consejo de medidas propuestas en virtud del título V del TFUE. El Reino Unido e Irlanda pueden notificar al Consejo, en un plazo de tres meses a partir de la presentación de una propuesta o iniciativa, o en cualquier momento después de su adopción, su deseo de participar en la adopción y aplicación de la medida propuesta. En cualquier momento, Dinamarca puede, de acuerdo con sus normas constitucionales, informar a los demás Estados miembros de que desea aplicar plenamente todas las medidas pertinentes adoptadas sobre la base del título V del TFUE.

15 Adoptada en Ginebra, Suiza, el 28 de julio de 1951 por la Conferencia de Plenipotenciarios sobre el Estatuto de los Refugiados y de los Apátridas (Naciones Unidas), convocada por la Asamblea General en su Resolución 429 (V), del 14 de diciembre de 1950. Entrada en vigor: 22 de abril de 1954, de conformidad con el artículo 43. Serie Tratados de Naciones Unidas, No 2545, Vol. 189, p. 137. En adelante, Convención de Ginebra de 1951. La Convención entra en vigor con carácter general el 22 de abril de 1954, para España el 14 de agosto de 1978 (BOE núm. 252, de 21 de octubre de 1978; corrección de errores en BOE núm. 272, de 14 de noviembre). Protocolo sobre el Estatuto de los Refugiados, entra en vigor con carácter general el 4 de octubre de 1967, para España el 14 de agosto de 1978 (BOE núm. 252, de 21 de octubre de 1978; corrección de errores en BOE núm.272, de 14 de noviembre).

16 Arts. 2 d) y f), junto con el art. 15 de la Directiva 2011/95.

${ }^{17}$ Una vez presentada la solicitud de protección internacional tienen derecho a un alojamiento, alimentación y vestido, proporcionados en especie o en forma de asignaciones financieras o de vales, o una combinación de las tres, y una asignación para gastos diarios (art. $2 \mathrm{~g}$ ). Y a que se determine su estatuto en un procedimiento donde se debe garantizar el acceso a asesoramiento legal, e incluso la presentación de un recurso en caso de inadmisión a trámite de su solicitud o denegación de uno o los dos estatutos. Directiva 2013/33. 
a territorio europeo, estas personas se vean avocadas a emprender viajes tan peligrosos en su necesidad imperiosa de llegar a Europa y presentar su solicitud de protección.

El 19 de abril de 2015 es una fecha clave en todo este proceso. Tras producirse el naufragio con mayor número de víctimas mortales de todas las sucedidas en el Mediterráneo, se celebra una reunión de los Ministros de Asuntos Exteriores, donde la Comisión presenta un Plan de 10 puntos que luego se desarrollarían en la "Agenda Europea de Migración" y donde se reconoce que la política europea "no ha estado a la altura" y se debían adoptar acciones prioritarias para hacer frente a la crisis ${ }^{18}$. A partir del consenso alcanzado en la reunión del Consejo Europeo de 23 de abril de 2015 y tras la adopción de la Agenda Europea de Migración, se ponen en marcha varias medidas la mayor parte de las cuales inciden en la doctrina asentada de contención de flujos fuera de territorio europeo, el retorno y de lucha contra la inmigración irregular, y solo en menor medida se adoptan decisiones en el marco de la llamada "solidaridad internacional"(reparto de la responsabilidad en materia de personas refugiadas con terceros países afectados), así como entre los socios comunitarios. En el marco de ambos tipos de medidas, se han puesto en marcha actuaciones insólitas hasta el momento. Así, en el ámbito de la lucha contra la inmigración irregular, se ha activado una operación militar de gestión de crisis para luchar contra el tráfico ilícito de personas. Y en el marco de las medidas que inciden en el reparto de la responsabilidad en materia de

${ }^{18}$ La Comisión reconoce que la reacción europea estaba siendo insuficiente y, por ello, establece medidas a corto plazo para estabilizar la situación actual, así como medidas a más largo plazo para establecer un sistema sólido que resista la prueba del tiempo. La lista de acciones prioritarias establece las medidas clave inmediatamente necesarias en términos de: i) medidas operativas; ii) ayuda presupuestaria y iii) aplicación del Derecho de la Unión y de acción exterior (en la que se incluye la operación militar de gestión de crisis). Estas son: Triplicar la capacidad y activos de las operaciones conjuntas de la Agencia Frontex, (Tritón y Poseidón), en 2015 y 2016; la Activación del sistema de emergencia en virtud del artículo 78, apartado 3, del Tratado para distribuir mejor a los solicitantes de asilo en Europa; crear "puntos calientes" o "Hotspot", coordinados por la Comisión, en los cuales tanto la Agencia Europea de Apoyo al Asilo (EASO), como Frontex y Europol trabajarán sobre el terreno en los Estados miembros que se hallan en primera línea con objeto de identificar, registrar y tomar las huellas dactilares de las personas migrantes, con la mayor celeridad posible, y de coordinar el retorno; Movilizar 60 millones de euros adicionales de financiación de emergencia para los Estados miembros de primera línea; Disponer un programa de reasentamiento dotado con 50 millones de euros y destinado a transferir 20.000 personas a Europa de forma segura y legal; Asignar 30 millones de euros para los programas regionales de desarrollo y protección empezando por los del norte de África y el Cuerno de África en 2015 y 2016; Recopilar información por parte de Europol con la contribución de todas las agencias de la UE con objeto de desmantelar las redes delictivas; Establecer operaciones de la Política Común de Seguridad y Defensa (PCSD) en el Mediterráneo para la captura y destrucción de embarcaciones y, yendo más allá, la migración se convertirá en un componente específico de las actuales misiones de la Política Común de Seguridad y Defensa (PCSD) ya desplegadas en Níger y Mali, que se reforzará en materia de gestión de fronteras; Establecer un centro polivalente piloto en Níger en colaboración con la OIM y ACNUR; Desplegar agentes migratorios europeos en las Delegaciones de la UE en los países clave de tránsito. Comisión Europea. Agenda Europea de Migración. COM (2015) 240 final, 13.05.2015. 
personas refugiadas, se ha decidido la reubicación de aquellas manifiestamente necesitadas de protección desde Grecia e Italia al resto de Estados miembros de la Unión. Según el Comisario de Migración, Asuntos de Interior y Ciudadanía, Dimitris Avramopoulos, "los planes de reubicación y reasentamiento, junto con el reforzamiento de las operaciones Tritón y Poseidón y el Plan de lucha contra los traficantes, responden a los problemas más urgentes a los que tenemos que hacer frente"19. Dada, pues, la prioridad que se ha dado a estas medidas y su carácter novedoso, se dedicará el presente trabajo a su análisis.

En el primer apartado se examinará el protagonismo que ha adquirido la lucha contra el tráfico de personas hasta el punto de utilizar medios militares para su desmantelamiento y qué dificultades plantean este tipo de operaciones en el marco del cumplimiento de las obligaciones derivadas del Derecho Internacional de las Personas Refugiadas, así como la necesidad de legislar sobre la creación de vías de acceso seguro a territorio europeo para aquellas personas necesitadas de protección. En el segundo apartado, se estudiará la decisión de activar el sistema de emergencia del artículo 78.3 del Tratado de Funcionamiento de la Unión Europea (TFUE) y las medidas provisionales adoptadas con objeto de atender a las situaciones de afluencia masiva de personas desplazadas y que supondrán la reubicación de parte de las mismas, en los próximos dos años.

\section{Tráfico de personas y operaciones militares de gestión de crisis. La necesidad de legislar sobre vías de acceso seguro a la protección}

Ante las medidas adoptadas para reforzar las fronteras europeas y la ausencia de cauces legales y seguros para acceder a la protección internacional, muchas personas que huyen de la persecución o los daños graves -al igual que otros migrantes- se ven obligadas a acudir a las redes delictivas de traficantes para llegar a territorio europeo. Precisamente, la lucha contra este medio de entrada irregular a Europa ha obtenido un inusitado protagonismo en mitad de la crisis del Mediterráneo. Partiendo de la consideración de estas actividades como una amenaza a la seguridad de la Unión y su desmantelamiento como vía para evitar la pérdida de vidas en el mar, se han adoptado medidas de carácter militar insólitas en este campo.

El tráfico ilícito de migrantes forma parte de los supuestos considerados "delincuencia transfronteriza grave y organizada" ${ }^{20}$ (junto con el tráfico de

\footnotetext{
${ }^{19}$ Comisión Europea. Comunicado de Prensa, Bruselas 27 de mayo de 2015.

${ }^{20}$ Protocolo contra el tráfico ilícito de migrantes por tierra, mar y aire, 15 de noviembre de 2000, que complementa la Convención de Naciones Unidas contra la Delincuencia Organizada Transnacional. Art. 3 a): "Por 'tráfico ilícito de migrantes' se entenderá la facilitación de la entrada ilegal de una persona en un Estado Parte del cual dicha persona no sea nacional o residente permanente 
drogas, la delincuencia financiera, la ciberdelincuencia, la trata de personas...) y su desarticulación ya fue considerado uno de los cinco objetivos estratégicos de la Estrategia Europea de Seguridad Interior $(2010)^{21}$, si bien diluido con el contrabando de drogas y la trata de personas. De forma más precisa, en la Estrategia de Seguridad Nacional de España (2013) se consideran directamente "los flujos migratorios irregulares" entre las amenazas a la seguridad nacional y entre las líneas de acción estratégicas "la ordenación de esos flujos". Según esta estrategia, las dinámicas que han experimentado en las últimas décadas, así como su volumen, los ha transformado en un fenómeno con "implicaciones para la política de seguridad"22. En respuesta a esta prioridad, en los últimos años se opta por reforzar la seguridad de las fronteras con un mayor uso de las nuevas tecnologías en los controles fronterizos, así como en la vigilancia de fronteras, y la adopción de medidas encaminadas al retorno y la readmisión de personas migrantes en situación irregular a sus países de origen o tránsito, todo ello bajo la coordinación de la Agenda europea para la gestión de la cooperación operativa en las fronteras exteriores de los Estados miembros (FRONTEX ${ }^{23}$ ).

Sin embargo, la tragedia de Lampedusa -naufragio ocurrido el 3 de octubre de 2013 en el que perdieron la vida 360 personas- inicia el debate sobre la responsabilidad europea en el salvamento de vidas en el mar, al tiempo que empieza a tomarse en consideración la intervención militar frente a las mafias que facilitan y se lucran de la necesidad imperiosa de estas personas por llegar a Europa. Italia, tras poner en marcha de la operación Mare Nostrum que llegó a rescatar hasta 180.000 personas en un año, propone el 24 de octubre de 2013 a la Alta Representante de la Unión Europea para Asuntos Exteriores y Política de Seguridad una misión naval y aérea que tuviera como objeto destruir las embarcaciones de estas redes, al estilo de la operación "Atalanta" contra la piratería. El Consejo Europeo, a pesar de valorar el valor de inteligencia y conocimiento situacional que tendría una operación de ese tipo, decide finalmente descartarla y opta por lanzar una misión mixta de gestión de fronteras (FRONTEX) y apoyo humanitario (TRITON), que sustituiría a Mare Nostrum, aunque con menores medios, presupuesto y radio de actuación ${ }^{24}$.

con el fin de obtener, directa o indirectamente, un beneficio financiero u otro beneficio de orden material".

${ }^{21}$ Comisión Europea. La Estrategia de Seguridad Interior de la UE en acción: cinco medidas para una Europa más segura. COM (2010) 673 final. 22.11.2010.

${ }^{22}$ Gobierno de España. Presidencia del Gobierno. Estrategia de Seguridad Nacional. Un proyecto compartido. 2013, p. 32.

${ }^{23}$ Reglamento (UE) del Parlamento Europeo y del Consejo de 25 de octubre de 2011 que modifica el Reglamento (CE) no 2007/2004 del Consejo, por el que se crea una Agencia Europea para la gestión de la cooperación operativa en las fronteras exteriores de los Estados miembros de la Unión Europea. DO L, 304, 22.11.2011.

${ }^{24}$ En la reunión en la que se discuten las posibilidades de la propuesta italiana, se consideraron los problemas aparejados a la militarización de un problema de carácter humanitario, así como las dificultades de coordinación de una operación militar con FRONTEX, pero también: “(...) the 
Con la nueva tragedia ocurrida el 20 de abril de 2015, la perspectiva cambia y se declara la "guerra contra los traficantes" 25 . Tanto en la Agenda Europea de Seguridad $\left(2015^{26}\right)$ como en la Agenda Europea de Migración $\left(2015^{27}\right)$ la lucha contra el tráfico ilícito de inmigrantes se aborda como una prioridad más definida, en el marco de la lucha contra las redes de delincuencia organizada. En la Agenda Europea de Seguridad se parte del convencimiento de que "cuanto antes pueda detenerse este tráfico, menor será el riesgo de tragedias humanas como las observadas recientemente en el Mediterráneo" ${ }^{28}$ y para ello resulta clave la asociación con terceros países, ofreciendo asistencia para ayudar a los países de tránsito clave a prevenir y detectar las actividades de tráfico lo antes posible. Y en el caso de la Agenda Europea de Migración subraya la necesidad de "poner el punto de mira en las redes delictivas de traficantes", en cuyo ámbito y con independencia de otras actuaciones, se informa de la preparación de operaciones en el marco de la Política Común de Seguridad y Defensa (PCSD), con miras a "la identificación, captura y destrucción sistemática de las embarcaciones utilizadas por los traficantes"29. El 11 de mayo de 2015, la

potentially negative media impact ("battle ships against refugees", "European fortress") has to be taken into account. From legal perspective such an operation would have significant challenges which would need to be clarified in advance, in particular with regards to jurisdiction of different law enforcement actions on high seas and the responsibilities for the further processing of asylum applications, refugees and other migrants, compliance e.g. to the UN Convention and Protocol relating to the Status of Refugees as well as the EU Charter of Fundamental Rights, in particular the principle of non-refoulement. Furthermore, the increase of surveillance capabilities goes hand in hand with the increase of efficiency of SAR, which might transform into a counterproductive pull-factor. Finally, it also seems arguable that any possible CSDP mission at high sea will single-handedly bring results without involvement on the ground in capacity building, border management or development". Consejo de la Unión Europea: Migration Flows in the Southern Neighbourhood and their External Relations Perspective -Possible Avenues for Dialogue and Cooperation with Partner Countries, including Options for a CSDP Operation, 16394/13, COPS 490 COSI 132 COMAG 119 JAI 1020, 19.11.2013, p. 10.

${ }^{25}$ En una rueda de prensa, el Comisario Avramopoulos declara: “(...) the situation in the Mediterranean has to change now. We have to take action now. We will take action now. Our response is clear and unequivocal. Europe is declaring war on smugglers". Comisión Europea. Remarks by Commissioner Avramopoulos at the press conference in Castille Place, Malta, 23.04.2015.

${ }^{26}$ Comisión Europea. Agenda Europea de Seguridad. COM (2015) 185 final. 28.04.2015.

${ }^{27}$ Comisión Europea. Agenda Europea de Migración. Op. cit.

${ }^{28}$ Comisión Europea. Agenda Europea de Seguridad. op. cit, p. 20.

${ }_{29}$ Como complemento a estas operaciones, se disponen tres medidas adicionales: 1) reforzar la operación conjunta de Europol de información marítima (JOT MARE), con objeto de crear un punto de acceso único para la cooperación de las distintas agencias (Agenda Europea de Seguridad Marítima; Agenda europea de Control de la Pesca o Eurojust) sobre este tipo de tráfico; 2) que Frontex y Europol establezcan el perfil de las embarcaciones que podrían ser utilizadas por los traficantes, siguiendo patrones que permitan detectarlas y seguir sus movimientos; y 3) que Europol identifique los contenidos ilegales que los traficantes utilizan en internet para atraer a los migrantes y refugiados, y exigir su retirada. Comisión Europea. Agenda Europea de Migración, op. cit., pp. 4-5. El Plan de Acción de la UE contra el Tráfico Ilícito de Migrantes (2015-2020) solo se refiere a estas operaciones en un pequeño párrafo. En éste indica que se elaborará una lista de embarcaciones sospechosas que probablemente se vayan a utilizar en el Mediterráneo. En ella se incluirán, por ejemplo, embarcaciones registradas al final de su vida útil y embarcaciones para el desguace. Las agencias pertinentes de la UE y las autoridades de los Estados miembros deberían establecer criterios de riesgo para identificar 
Alta Representante de la Unión Europea para Asuntos Exteriores y Política de Seguridad informa al Consejo de Seguridad de las Naciones Unidas sobre estas medidas, insistiendo en la intención de la Unión Europea de actuar de conformidad con el Derecho Internacional y, en particular con el apoyo del Consejo de Seguridad ${ }^{30}$.

Una semana más tarde, se decide activar una operación militar de gestión de crisis (EUNAVFOR MED), a través de la Decisión PESC 2015/778, del Consejo de 18 de mayo de $2015^{31}$. Con esta operación se pretende contribuir a desarticular el modelo de negocio de las redes de tráfico ilícito y trata de personas en el Mediterráneo central meridional, realizando esfuerzos sistemáticos para detectar, capturar y eliminar los buques y medios que utilizan o que se sospeche que utilizan los pasadores de fronteras o los tratantes de personas, de conformidad con el Derecho internacional aplicable, incluidos la Convención de Naciones Unidas sobre el Derecho del Mar (CNUDM) y cualquier resolución del Consejo de Seguridad de las Naciones Unidas (art. 1 misión). Se trata de una operación diseñada en fases, que permite en un primer momento detectar y seguir las redes de migraciones mediante la recopilación de información y el patrullaje en alta mar (fase primera ya activada) y a posteriori, visitar, registrar, apresar y desviarlos buques sospechosos, en alta mar y en las aguas interiores del Estado ribereño con su consentimiento o de conformidad con una decisión del Consejo de Seguridad (segunda fase activada el 7 de octubre de $2015^{32}$ ). Y, en una última fase, de conformidad con cualquier

esas embarcaciones y garantizar que sean vigiladas sistemáticamente, utilizando Eurosur y las capacidades de todas las agencias. Concretamente, establece que: "Una vez garantizada la seguridad de las personas, las embarcaciones que los traficantes hayan utilizado o tuvieran previsto utilizar deberán ser sistemáticamente remolcadas a tierra o destruidas en el mar. La Comisión y las agencias pertinentes de la UE, en particular Frontex, proporcionarán a los Estados miembros ayuda financiera y técnica para remolcar las embarcaciones a tierra y desguazarlas". Comisión Europea. COM (2015) 285 final, 27.05.2015, p. 4.

${ }^{30}$ Véase un resumen de su intervención en: http://www.un.org/press/en/2015/sc11885.doc.htm

${ }^{31}$ Decisión (PESC) 2015/778 de 18 de mayo de 2015 relativa a una operación militar de la Unión Europea en el Mediterráneo central meridional (EUNAVFOR MED). DO L 122, 19.05.2015. De acuerdo con el art. 5 del Protocolo $n^{\circ} 22$ del TUE y TFUE, Dinamarca no participa en la elaboración y aplicación de decisiones y acciones de la Unión con implicaciones en el ámbito de la defensa. Por tanto, no participa ni está vinculada, ni financia esta operación (ver: considerando 12 de la Decisión).

Por Decisión (PESC) 2015/972 del Consejo de 22 de junio de 2015 por la que se pone en marcha una operación militar de la Unión Europea en el Mediterráneo Central Meridional (EUNAVFORMED) quedan aprobados el plan de la operación y las reglas de enfrentamiento relativos a la operación militar, así como la fecha de su puesta en marcha, esta es, el 22 de junio de 2015 (arts. 1 y 2). DO L 157, 23.06.2015.

${ }^{32} \mathrm{El}$ art. 2.2 concretamente dispone: a) en una primera fase, apoyará la detección y el seguimiento de las redes de migración mediante la recopilación de información y las patrullas en alta mar de conformidad con el Derecho internacional; b) en una segunda fase,

i) procederá a visitar, registrar, apresar y desviar en alta mar los buques sospechosos de ser utilizados para el tráfico ilícito o la trata de seres humanos, en las condiciones previstas en el Derecho internacional aplicable, incluidos la CNUDM y el Protocolo contra el tráfico ilícito de migrantes,

ii) de conformidad con cualquier resolución aplicable del Consejo de Seguridad de las 
Resolución del Consejo de Seguridad o el consentimiento del Estado ribereño, adoptar todas las medidas necesarias incluso la eliminación o inutilización, contra un buque que se sospeche se utiliza contra el tráfico ilícito o la trata de seres humanos, en el territorio de dicho Estado ${ }^{33}$.

Sólo 5 meses más tarde y contra todo pronóstico, se adopta la Resolución del Consejo de Seguridad 2240 (2015) de 9 de octubre de 2015y que pretende dar cobertura jurídica al paso a la segunda fase de la operación EUNAVFOR MED -ahora llamada Sophia ${ }^{34}-$, concretamente en Libia ${ }^{35}$. Téngase en cuenta, como reconoce el Consejo de Seguridad, que la reciente proliferación de tráfico de migrantes en el Mediterráneo se ha producido frente a las costas de Libia. La falta de control de los bandos enfrentados en este país sobre sus fronteras ha convertido su costa en el principal punto de salida de la inmigración irregular hacia Italia, una inmigración en la que se combinan, por un lado, los flujos migratorios motivados por razones económicas, y por otro, los refugiados/as que huyen de guerras civiles, dictaduras sangrientas y otros conflictos violentos en Siria, Eritrea, el Daesh, Malí y otros países africanos o de Oriente Próximo ${ }^{36}$.

Teniendo en cuenta las dificultades del Gobierno de Libia para gestionar eficazmente las corrientes migratorias en tránsito por su territorio y las repercusiones de este fenómeno en la estabilidad de Libia y en la región del Mediterráneo y, sobre todo, por el peligro para la vida de las personas que suponen estas actividades, el Consejo de Seguridad adopta tres decisiones básicas (dispositivos 7-10).

En primer lugar, decide autorizar a los Estados miembros, actuando individualmente o por conducto de organizaciones regionales, a inspeccionar los buques en alta mar frente a las costas de Libia, cuando se tengan motivos razonables para creer que han sido, están siendo o serán utilizados inminentemente para el tráfico de inmigrantes o la trata de personas desde Libia, aún sin el consentimiento del Estado del pabellón (el Derecho

Naciones Unidas o el consentimiento del Estado ribereño en cuestión, procederá a visitar, registrar, apresar y desviar, en alta mar y en las aguas interiores de dicho Estado, los buques sospechosos de ser utilizados para el tráfico ilícito o la trata de seres humanos, en las condiciones establecidas en dicha resolución o consentimiento;

${ }^{33}$ En virtud del art. $2.2 \mathrm{c}$ ): en una tercera fase, de conformidad con cualquier resolución aplicable del Consejo de Seguridad de las Naciones Unidas o el consentimiento del Estado ribereño en cuestión, adoptará todas las medidas necesarias, incluso la eliminación o inutilización, contra un buque y los medios relacionados que se sospeche que se utilizan para el tráfico ilícito o la trata de seres humanos, en el territorio de dicho Estado, en las condiciones establecidas en dicha resolución o consentimiento.

${ }^{34}$ Decisión PESC 1926 (2015) del Consejo, de 26 de octubre de 2015. DO L 281, 27.10.2015.

${ }^{35}$ La Resolución -redactada sobre un borrador británico- recibió 14 votos a favor y la abstención de Venezuela. Los actuales miembros no permanente del Consejo de Seguridad son: Angola (2016); Chad (2015); Chile (2015); España (2016); Jordania (2015); Lituania (2015); Malasia (2016); Nigeria (2015); Nueva Zelandia (2016); Venezuela (República Bolivariana de) (2016).

${ }^{36}$ Félix Arteaga y Carmen González Enríquez: "La respuesta militar a la crisis migratoria del Mediterráneo", ARI 40/2015, 22.07.2015. 
internacional autoriza a hacerlo con los barcos que no enarbolan pabellón o con la autorización del Estado del pabellón: dispositivos 5 y 6 de la Resolución), bajo tres condiciones: existe un límite temporal: un año a partir de la fecha de aprobación de la Resolución, por tanto, se autoriza a adoptar estas medidas desde el 18 de mayo de 2015 hasta el 18 de mayo de 2016; una obligación de comportamiento: que esos Estados miembros y las organizaciones regionales "hayan intentado de buena fe obtener el consentimiento de los Estados" (dispositivo 7); y una obligación de resultado: que "mantengan informados a los Estados del pabellón" (dispositivo 9).

En segundo lugar, decide autorizar a los Estados miembros, actuando individualmente o por conducto de organizaciones regionales, a apresar los buques inspeccionados cuando se confirme que están siendo utilizados para el tráfico de migrantes o la trata de personas desde Libia (dispositivo 8), con el mismo límite temporal (un año) y la misma obligación de información al Estado del pabellón citada anteriormente (dispositivo 9).

En tercer lugar, decide autorizar a los Estados miembros que actúen individualmente o por conducto de organizaciones regionales a emplear todas las medidas que dicten las circunstancias -lo que viene a incluir el uso de la fuerza- para hacer frente a los traficantes y tratantes al llevar a cabo las dos medidas anteriores: inspección y apresamiento, solo en alta mar frente a las costas de Libia (no en sus aguas interiores o en su territorio, a diferencia de lo que pretendía la Decisión PESC en su tercera fase, para la que este Resolución no daría cobertura jurídica).

Con independencia de los interrogantes jurídicos, de todo tipo, que suscitan la Decisión PESC y esta Resolución del Consejo de Seguridad ${ }^{37}$ y de la manifiesta inutilidad de las mismas para la finalidad perseguida ${ }^{38}$,

\footnotetext{
${ }^{37}$ Véase inter alia: Ziccardi, Giuliana: "The EUNAVFOR MED Operation and the use of force", American Society of International Law, volume 19, issue 27, 18.12.2015.

${ }^{38}$ El problema del tráfico de personas es mucho más complejo y difícilmente una operación militar de estas características puede enfrentarlo. Según Félix Arteaga y Carmen González Enríquez, "las llamadas "mafias" de inmigración son redes muy laxas, compuestas por una gran variedad de individuos sin una relación jerárquica entre sí, que operan desde los países de origen hasta los de destino, con múltiples funciones, y con un negocio millonario que se reparte entre muchos: el que informa y recluta en origen, el propietario del camión que cruza el desierto, su conductor, el funcionario de fronteras que se deja sobornar en algún país de paso, el dueño del local donde se acoge a los inmigrantes a la espera de que salga el barco, el que los alimenta en la espera, el dueño del barco, su piloto, el que les alecciona sobre cómo comportarse al llegar a suelo europeo, el que les ayuda en destino, etc... Se les culpa de la inmigración irregular, pero sólo son un medio necesario para cumplir un deseo, ya sea mejorar social y económicamente o vivir en un país en paz. En cualquier caso, por su naturaleza, estas redes no son destruibles con medios militares. Sólo un trabajo policial y judicial, complicado por su carácter transnacional, podría debilitarlas". Parece imprescindible, pues, una actuación sobre el terreno que la Resolución no autoriza y que algunos delegados en el Consejo de Seguridad ya han avanzado que debe cumplirse en sus estrictos límites. Así, el delegado ruso en el Consejo de Seguridad dejó claro los estrictos límites de la Resolución y que “(T)enemos la intención de vigilar estrechamente todas las medidas que deberán adoptarse en relación con los buques presentes en esa región".

Así las cosas, la operación EUNAVFOR MED Sophia parece más encaminada al salvamento de
} 
me gustaría subrayar tres problemas básicos que suscitan en lo que aquí concierne.

En primer lugar, tanto la Decisión PESC que activa la operación militar de gestión de crisis EUNAVFOR MED Sophia, como la Resolución del Consejo de Seguridad parten de la base de que las tragedias que se producen en el Mediterráneo son consecuencia del tráfico ilícito(o de la trata, obviando por completo -no sin interés- que este fenómeno no suele utilizar estos cauces para trasladar a los seres humanos que serán tratados en otros países) y no reconocen que la utilización de las mafias es solo un síntoma más del problema. La Resolución 2240 observa con preocupación que, en algunos casos, las muertes se produjeron a causa de la información engañosa de las organizaciones delictivas y en ningún momento se mencionan las causas que realmente empujaron a estas personas a hacer uso de estos medios ilegales que, sobre todo, ponen en peligro su vida y seguridad.

En segundo lugar, la utilización de una operación militar o la autorización del uso de la fuerza en el marco del capítulo VII de la Carta de Naciones Unidas supone la militarización de una crisis de carácter humanitario, lo cual viene a convertirse en una peligrosa vuelta de tuerca del proceso de securitización que ha caracterizado el nacimiento y desarrollo de la Política Europea de Asilo y Migración. Ante los evidentes riesgos para la vida de las personas migrantes y refugiadas de toda operación militar ${ }^{39}$, téngase en cuenta también que estos procesos inciden en la consabida criminalización de seres humanos que no son delincuentes sino personas en peligro ${ }^{40}$.

vidas. Según la Decisión PESC, de conformidad con el CNUDM, el Convenio Internacional para la Seguridad de la Vida en el Mar (SOLAS) y el Convenio Internacional sobre búsqueda y salvamento marítimo (SAR), la operación EUNAVFOR MED Sophia está obligada a asistir a las personas en peligro en el mar y a llevar a los supervivientes a un lugar seguro. Así, se da cuenta en su página web de 44 operaciones de salvamento y hasta 8.500 vidas salvadas hasta la fecha. Pueden verse algunas de estas operaciones en: http://eeas.europa.eu/csdp/missions-and-operations/eunavfor-med/ index en.htm

Más allá de la utilidad o no de este tipo de operaciones militares en la lucha contra el tráfico de personas, lo cierto es que no se puede olvidar la necesidad de abordar las causas que se encuentran el origen de estos desplazamientos. Como afirmó el representante del Chad en el Consejo de Seguridad: "En consecuencia, en nuestra humilde opinión, emprender una lucha contra los traficantes en alta mar sin abordar las causas radicales de la crisis de migración y refugiados no sería una solución viable, sobre todo habida cuenta de que la mayoría de esos traficantes se encuentran en tierra firme. Por ese motivo, consideramos que una estrategia amplia que haga hincapié en las causas subyacentes de la migración, entre las que se encuentran la pobreza, la indigencia, la crisis económica y social, y los conflictos armados, nos podría ayudar a buscar soluciones adecuadas y duraderas".

${ }^{39}$ La Resolución del Consejo de Seguridad autoriza a emplear "todas las medidas que dicten las circunstancias", dando absoluta prioridad a la seguridad de las personas (dispositivo 10), a las que, no obstante, menciona al mismo nivel que al medio marino o la navegación.

${ }^{40}$ En un informe de la Asamblea Parlamentaria de la OTAN, se afirma directamente que: "el exilio masivo ha demostrado como los refugiados pueden rápidamente convertirse en un acelerador de la inestabilidad y tensión internacionales". OTAN. Asamblea Parlamentaria (Mediterranean and Middle East Special Group). The Sirian Refugee Crisis and its impact on the Region, Noviembre 2014, para.4, p. 1. 
Y, por último, quisiera insistir en que estas operaciones pueden comprometer el debido cumplimiento de las obligaciones que dimanan del Derecho de la Unión Europea, en concreto, del artículo 3.5 del TUE (en sus relaciones con el mundo, la Unión erradicará la pobreza y protegerá los derechos humanos), el artículo 78.1 TFUE donde se dispone que la Unión desarrollará una Política común de Asilo, de conformidad con la Convención de Ginebra de 1951 sobre el Estatuto de las Personas Refugiadas y, específicamente, los artículos 18 y 19 de la Carta de Derechos Fundamentales de la Unión Europea (CDFUE) que garantizan el derecho de asilo y el principio de no devolución. Piénsese que el derecho a huir está implícito en el derecho de asilo. El Consejo de Seguridad de Naciones Unidas lo sabe y por eso se apresura a manifestar, en el dispositivo 12 de la Resolución, que ésta tiene por objeto desarticular los grupos delictivos organizados que se dedican al tráfico ilícito de migrantes "y no tiene como fin socavar los derechos humanos de las personas o impedirles que soliciten protección en virtud del Derecho Internacional de los Derechos Humanos y el Derecho Internacional de los Refugiados". Sin embargo, he aquí la clave. No se establece cómo se va a hacer compatible el mandato de la operación con ese derecho a solicitar protección internacional o el efectivo cumplimiento del principio de no devolución que ni siquiera se nombra. La Resolución del Consejo de Seguridad reconoce que entre los migrantes sujetos a tráfico puede haber personas que "respondan a la definición de refugiado formulada en la Convención de 1951 sobre el Estatuto de los Refugiados y su Protocolo de 1967" e incluso insiste en la obligación de tratar a las personas migrantes con humanidad y dignidad y en estricto cumplimiento de las obligaciones derivadas del Derecho Internacional de los Derechos Humanos y el Derecho Internacional de las Personas Refugiadas (dispositivo 13). Por tanto, la acción prioritaria ha de ser desembarcar a estas personas en un "lugar seguro" que no solo debe implicar la protección frente a un posible peligro físico sino que también debe tener en cuenta la dimensión de los derechos fundamentales en cuanto al lugar del desembarco ${ }^{41}$.

En las circunstancias actuales, se debe disponer, de forma expresa, el desembarco en un puerto seguro europeo, con objeto de que puedan ejercer su derecho a solicitar protección internacional (no basta con el representante británico en el Consejo de Seguridad así lo afirmara ${ }^{42}$ ), así como la prohibición de su devolución tal y como ha sido definido en la CDFUE, la jurisprudencia del Tribunal de Justicia de la Unión Europea (TJUE) y del Tribunal Europeo de Derechos Humanos (TEDH), esto es, que ninguna persona puede ser

\footnotetext{
${ }^{41}$ Asamblea Parlamentaria del Consejo de Europa. Resolución 1821 (2011). 21.07.2011.

${ }^{42}$ El Sr. Rycroft señaló: "Permítaseme ser claro. Todas las medidas que se apliquen serán proporcionadas, con miras a respetar los límites autorizados por la resolución y serán utilizadas solo contra los traficantes y las embarcaciones vacías. Todos los migrantes encontrados durante la operación serán llevados a Europa como parte de los procedimientos establecidos".
} 
desembarcada en un país, forzada a entrar, conducida o entregada de algún otro modo a sus autoridades, incumpliendo el principio de no devolución cuando, entre otros supuestos, exista un riesgo grave de que se vea expuesta a sufrir pena de muerte, tortura, persecución o cualquier otra pena o trato inhumano o degradante o cuando su vida o su libertad estén amenazadas por motivos de raza, religión, nacionalidad, pertenencia a determinado grupo social u opiniones políticas o cuando exista un riesgo grave de que sea expulsada, trasladada o extraditada a otro país incumpliendo este principio (así se ha incorporado en la normativa relativa a las operaciones coordinadas por Frontex $\left.{ }^{43}\right)$.La interceptación de migrantes y su devolución a Libia o a cualquier otro país donde no existan garantías de protección frente a estos daños podría comprometer la responsabilidad de los Estados miembros implicados.

El TEDH ya tuvo ocasión de comprobar la compatibilidad con el CEDH de una operación de rescate y devolución a Libia de once personas somalíes y trece personas eritreas por parte de buques militares italianos. En el caso Hirsi Jamaa y Otros contra Italia, de 23 de febrero de $2012^{44}$, la Alta Corte europea dispuso

${ }^{43}$ El Código de Fronteras Schengen exige a los Estados que lleven a cabo actividades de vigilancia de fronteras para evitar, inter alia, el cruce no autorizado de fronteras, sin embargo esta obligación ha de ser compatible con el pleno respeto al principio de no devolución. El Reglamento 1168/2011 que modifica el Reglamento de creación de Frontex pretende, entre otras cosas, revisar el mandato de la Agencia, con objeto de que las operaciones respeten íntegramente los derechos fundamentales y los derechos de las personas refugiadas y solicitantes de asilo, incluida en particular la prohibición de devolución tal y como ha sido interpretada por el TEDH y el TJUE. Véanse en particular los considerandos 29 y 30 donde se hace mención expresa al derecho de asilo, principio de no devolución y la Convención de Ginebra de 1951 y, especialmente, la inserción del artículo 2.1 b) "1.bis: De conformidad con el Derecho de la Unión y el Derecho internacional ninguna persona podrá ser desembarcada en un país ni entregada a sus autoridades si ello vulnera el principio de no devolución, o si existe el riesgo de que sea expulsada de tal país o repatriada a otro vulnerando dicho principio. Se atenderá a las necesidades especiales de los niños, de las víctimas de la trata de personas, de las personas que necesitan asistencia médica, de las personas que necesitan protección internacional y de otras personas vulnerables de conformidad con el Derecho de la Unión y el Derecho internacional". Reglamento 1168/2011 del Parlamento Europeo y del Consejo de 25 de octubre de 2011 que modifica el Reglamento (CE) no 2007/2004 del Consejo, por el que se crea una Agencia Europea para la gestión de la cooperación operativa en las fronteras exteriores de los Estados miembros de la Unión Europea, DO L 304, 22.11.2011.

Y en relación con la cooperación de la que se encarga la Agencia, se han establecido normas específicas para la actividades de vigilancia fronteriza llevadas a cabo por unidades marítimas, terrestres y áreas de un Estado miembro en la frontera marítima de otros Estados miembros o en alta mar en el marco de la cooperación operativa coordinada por la Agencia. En este sentido es fundamental el art. 4 del Reglamento 656/2014 de 15 de mayo de 2014 donde se disponen las obligaciones en materia de protección de derechos fundamentales y principio de no devolución. Reglamento 656/2014 del Parlamento Europeo y del Consejo de 15 de mayo de 2014 por el que se establecen normas para la vigilancia de las fronteras marítimas exteriores en el marco de la cooperación operativa coordinada por la Agencia Europea para la Gestión de la Cooperación Operativa en las Fronteras Exteriores de los Estados miembros de la Unión Europea, DO L 189, 27.06.2014 (en adelante, Reglamento 656/2014).

${ }^{44}$ Los nacionales somalíes y eritreos formaban parte de un grupo de aproximadamente 200 individuos que abandonaron Libia a bordo de tres embarcaciones con objeto de llegar a la costa italiana. El 6 de mayo de 2009, cuando los navíos se encontraban a 35 millas náuticas de Lampedusa, en el área de responsabilidad del servicio de búsqueda y salvamento de Malta, fueron interceptados por tres buques del servicio de vigilancia aduanera de la policía italiana y de los guardacostas. Fueron 
que la naturaleza especial del medio marítimo no implica la existencia de una zona de no derecho (caso Hirsi§178) en la que los Estados estén excluidos de las obligaciones internacionales que derivan del Derecho Internacional de los Derechos Humanos o el Derecho Internacional de las Personas Refugiadas. Siempre que ejerzan control sobre estas personas ${ }^{45}$, incluso aunque se trate de operaciones de salvamento (caso Hirsi, §79), están obligados a velar por el efectivo cumplimiento del artículo $3 \mathrm{CEDH}$ (proscripción de la tortura y las penas o tratos inhumanos o degradantes) y, por tanto, a no expulsar a esos migrantes a un Estado donde existen razones fundadas para pensar que podría enfrentarse a ese riesgo, ni a otro cualquiera que a su vez pudiera devolverles al lugar donde temen sufrir persecución o daño grave ${ }^{46}$. Esta obligación tiene carácter absoluto y no exime de su cumplimiento el hecho de que nos enfrentemos a afluencias masivas (caso Hirsi, §122); incluso es independiente de que estas personas hayan o no solicitado protección en los buques que los han rescatado o interceptado (caso Hirsi, §133). Las normas sobre salvamento de personas en el mar y las que rigen la lucha contra el tráfico de seres humanos imponen sobre los Estados el deber de cumplir con las obligaciones derivadas del principio de no devolución (caso Hirsi, §134).En consecuencia, toda operación militar de lucha contra el tráfico de personas que haya interceptado una embarcación con personas migrantes debe ponerlas a salvo, proceder a la identificación de las personas y trasladarlas a un país seguro que, en la situación actual, solo puede ser europeo ${ }^{47}$.

trasladados a buques militares italianos y devueltos a Libia en base a un acuerdo de cooperación entre ambos países que había entrado en vigor el 4 de febrero de 2009. Durante la travesía no les informaron de su destino verdadero y no intentaron identificarlos. Caso HirsiJamaa y Otros contra Italia, de 23 de febrero de 2012, paras. 9, 10, 11.

45 Según el artículo 1 del CEDH, las Altas Partes contratantes tienen la obligación de "reconocer" a toda persona dependiente de su "jurisdicción" los derechos y libertades definidos en el Título I del Tratado. Aunque la jurisdicción de un Estado es esencialmente territorial, el Tribunal ha aceptado, en casos excepcionales, que ciertas acciones llevadas a cabo por las Altas Partes contratantes, fuera de su territorio, pueden constituir un ejercicio de su jurisdicción en el sentido del artículo 1, cuando un Estado, mediante agentes que operan fuera de su territorio, ejerza control y autoridad (jurisdicción) sobre un individuo. Donde exista una relación de control sobre otro existirá el ejercicio de jure por parte del Estado en cuestión y, por tanto, la obligación de garantizar todos los derechos y libertades del Convenio. En el caso Hirsi, llega a la conclusión que la operación llevada a cabo por Italia constituye efectivamente un ejercicio extra-territorial de jurisdicción por parte de Italia, que implicó la responsabilidad del Estado en relación con la violación del art. 3 del CEDH y del art. 4 del Protocolo $4^{\mathrm{o}}$ al Convenio. Vid. paras. $70 \mathrm{y}$ ss.

${ }^{46}$ En relación con Siria, el TEDH ya ha tenido oportunidad de condenar la devolución a este país en el caso L.M contra Rusia donde se considera que viola el art. 2 y 3 del CEDH. Caso L.M. contra Rusia, de 15 de octubre de 2015.

${ }^{47}$ El art. 2.4 de la Decisión PESC 778 (2015) dispone que "La EUNAVFOR MED podrá recoger, de conformidad con la normativa aplicable, datos personales acerca de las personas que suban a bordo de los buques que participen en la EUNAVFOR MED relativos a características que puedan ayudar en su identificación, incluidas impresiones dactilares, así como los siguientes datos, con exclusión de otros datos personales: apellidos, apellidos de soltera, nombres y cualesquiera alias o apodos; fecha y lugar de nacimiento, nacionalidad, sexo; lugar de residencia, profesión y paradero; permisos de conducción, documentos de identidad y datos del pasaporte. Podrá transmitir esos datos y datos 
Como puede observarse es necesario estar en territorio europeo para poder optar a la citada protección internacional. El acervo comunitario en el ámbito del asilo tiene como objetivo garantizar el derecho de asilo, tal y como queda establecido en el artículo 18 de la CDFUE, y de conformidad con el Convenio de Ginebra de 1951 y con otros tratados aplicables. Sin embargo, este acervo, incluida la Directiva 2013/32 es aplicable únicamente a aquellas solicitudes de protección internacional formuladas en el territorio de los Estados miembros, lo cual incluye fronteras, áreas de tránsito y, en el contexto de las fronteras marítimas, las aguas territoriales de los Estados miembros. De igual forma se manifiesta la Directiva 2013/33 ${ }^{48}$. Así las cosas, la cuestión irresuelta que esta lucha contra el tráfico de personas y la pérdida de vidas en el mar ha puesto sobre la mesa es realmente la escasez de vías de acceso a territorio europeo que sean efectivas, legales y seguras, con objeto de solicitar protección. Tal y como ha subrayado, en mitad de esta crisis, el Comité Ejecutivo de ACNUR -compuesto por los representantes gubernamentales de los Estados firmantes de la Convención ginebrina-: "la protección internacional, incluida la protección contra la devolución empieza con la capacidad de las personas necesitadas de

relacionados con los buques y los equipos utilizados por dichas personas a las fuerzas o cuerpos de seguridad correspondientes de los Estados miembros o a los organismos competentes de la Unión". El proceso de identificación de las personas en peligro es fundamental en aras al cumplimiento del principio de no devolución. Se tratará de una disposición potestativa en caso de que vayan a ser trasladados a un puerto europeo. Sin embargo, si el traslado se realizase al país de salida del barco se ha de tener en cuenta la jurisprudencia del TEDH en relación con la proscripción de las expulsiones colectivas, en virtud de la cual, se debe garantizar la identificación de las personas con la asistencia de intérpretes y asistentes legales y un examen previo de la situación individual de cada demandante (caso Hirsi, §185).

Así, en relación con las operaciones coordinadas por Frontex, según el art. 4.3 del Reglamento 656/2014: Durante la operación marítima, antes de que las personas interceptadas o rescatadas sean desembarcadas, obligadas a entrar en un tercer país, conducidas o entregadas de algún otro modo a las autoridades de un tercer país y teniendo en cuenta la evaluación de la situación general en ese tercer país, de conformidad con el apartado 2, las unidades participantes deberán, sin perjuicio del artículo 3, utilizar todos los medios para identificar a las personas interceptadas o rescatadas, evaluar sus circunstancias personales, informarles de su destino de una manera que las personas comprendan, o sea razonable presumir que comprenden y darles la oportunidad de expresar las razones para creer que el desembarco en el lugar propuesto representaría un incumplimiento del principio de no devolución. A tal efecto, el plan operativo incluirá, en caso necesario, mayores detalles sobre la disponibilidad en tierra de personal sanitario, intérpretes, asesores jurídicos y otros expertos pertinentes del Estado miembro de acogida y de los Estados miembros participantes. Cada unidad participante incluirá, como mínimo, a una persona con formación básica de primeros auxilios. El informe mencionado en el artículo 13 deberá, con base en la información que facilite el Estado miembro de acogida y los Estados miembros participantes, incluir más detalles sobre los casos de desembarco en terceros países y sobre cómo fue aplicado por las unidades participantes cada elemento de los procedimientos establecidos en el párrafo primero del presente apartado para garantizar el cumplimiento del principio de no devolución".

${ }^{48}$ Según el art. 3 de la Directiva 2013/33: "La presente Directiva se aplicará a todos los nacionales de terceros países y apátridas que presenten una solicitud de protección internacional en el territorio, incluida la frontera, en las aguas territoriales o en las zonas de tránsito de un Estado miembro, siempre y cuando se les permita permanecer en su territorio en calidad de solicitantes, así como a los miembros de su familia si quedan cubiertas por la solicitud de protección internacional de conformidad con el Derecho nacional". 
protección internacional de poder acceder a un territorio". El cierre de fronteras, las restricciones en la concesión de visados, el aumento de las medidas de vigilancia y las devoluciones han acentuado los peligros a los que se enfrentan las personas que buscan seguridad. La imposibilidad de viajar de manera legal ha provocado que se recurra cada vez más a traficantes y que hayan aumentado los riesgos en materia de protección. Los países participantes en esta resolución llegaron al firme convencimiento de que centrarse únicamente en la disuasión, en la adopción de medidas unilaterales de control de fronteras o en el desmantelamiento de los traficantes agravará los peligros y no hará sino modificar las rutas de viaje ${ }^{49}$. La Agencia de Derechos Fundamentales de la Unión (FRA) ha denunciado como en 2010, cuando Siria aún no estaba en guerra, la Unión concedió 30.000 visados para personas de este país, mientras que 2013, tras el estallido del conflicto no concedió ninguno ${ }^{50}$. No es de extrañar, por tanto, el incremento de las llegadas a Europa por estas vías irregulares e inseguras. Así, resulta esencial crear medios de acceso seguro a territorio europeo para las personas en necesidad de protección. Sólo estas vías erradicarían el tráfico de personas dejando sin sentido su objeto. A pesar de que la Comisión reconoce, en la Agenda Europea de Migración, que hay que evitar que estas personas vulnerables se vean forzadas a recurrir a las redes delictivas de traficantes y tratantes y que para ello "es preciso proponerles vías seguras y legales para llegar a la UE", lo cierto es que solo aborda una de estas vías, el "reasentamiento" y apenas menciona otras opciones que deja a la voluntad (ausente) de los Estados ${ }^{51}$. Además, en su Recomendación de 8 de junio de 2015 ,en la que establece el primer proyecto piloto voluntario de reasentamiento, sólo dispone 20.000 plazas para el conjunto de la Unión Europea $^{52}$. Comparados con los 6.380 reasentados en toda la Unión en 2014,

\footnotetext{
49 Asamblea General de Naciones Unidas. Comité Ejecutivo del Programa del Alto Comisionado. Nota sobre Protección Internacional. A/AC.96/1145, 02.07.2015, paras. 39 y 41.

${ }^{50}$ FRA (European Union Agency for Fundamental Rights): Legal Entry Channels to the EU for persons in need of International Protection, FRA Focus, 02/2015.

51 En la Agenda Europea de Migración puede leerse: "Además, los Estados miembros deben hacer pleno uso de las otras vías legales a disposición de las personas que necesitan protección, en particular el patrocinio privado o no gubernamental y los permisos de residencia humanitarios, así como las disposiciones relativas a la reagrupación familiar". Comisión Europea: Agenda Europea de Migración, op.cit., p. 6. Nada se indica sobre la posibilidad de solicitar protección en las embajadas de los Estados miembros en el exterior, una opción que no impide el sistema europeo común de asilo, pero que no regula. La anterior ley de asilo española contemplaba esta opción que ha sido finalmente eliminada de la actualmente vigente. En su lugar, la Ley 12/2009 se limita a permitir (art. 38) que los /as embajadores/as promuevan el traslado del/la solicitante de protección internacional a España "si corre peligro su integridad física". A falta de un Reglamento que concrete esta disposición no es posible saber en qué supuestos sería operativa, pero no cabe duda que dista mucho de suponer una vía más de solicitud de protección internacional como así hace suponer el enunciado de la disposición.

52 Según el considerando 3 de la Recomendación, hay actualmente un desequilibrio importante entre los Estados miembros por lo que respecta al compromiso de reasentar a personas. Solo quince Estados miembros y tres Estados asociados tienen un programa de reasentamiento (hay, además, otro Estado miembro que ha anunciado el inicio de un programa de este tipo), tres
} 
puede considerarse un incremento, pero resulta ridículo comparado con millones de personas refugiadas en los países limítrofes con Siria y otras zonas de conflicto. Según el considerando 7 de la Recomendación, la Comisión presenta esta Recomendación para evitar que las personas desplazadas necesitadas de protección tengan que recurrir a las redes delictivas de traficantes y tratantes, sin embargo, no parece que el esfuerzo sea suficiente habida cuenta de las cifras actuales $^{53}$.

\section{Reubicación de personas en necesidad manifiesta de protección desde Grecia e Italia. La solidaridad intra comunitaria}

Otra de las medidas novedosas que se han adoptado en el marco de esta crisis de personas refugiadas en Europa ha sido la decisión de reubicar a aquellas con manifiesta necesidad de protección desde Grecia e Italia al resto de países miembros. Se trata de una importante medida que coadyuva a incorporar una auténtica solidaridad intra-comunitaria en el sistema europeo común de asilo.

Téngase en cuenta que, en virtud del Reglamento Dublín III, las personas que huyen de la persecución u otros daños graves, y han conseguido llegar a territorio europeo, solo podrán presentar su solicitud de protección en un único Estado de la Unión Europea, que estará obligado a estudiarla y cuya decisión será vinculante

Estados miembros y un Estado asociado han aplicado medidas de reasentamiento con carácter ad hoc, mientras que los demás no participan en absoluto en esta tarea. En función de la clave de reparto que la propia Recomendación incluye, a España le corresponderían 1549 personas, esto es, un 7,75\% del total. FAMI financia cada reasentamiento con 10.000 euros por persona. Recomendación (UE) 2015/914 de la Comisión, de 8 de junio de 2015 sobre un programa europeo de reasentamiento. DO L 148, 13.06.2015.

España era de los países que no disponían una normativa concreta en relación con el reasentamiento y solía responder ad hoc a los llamamientos de ACNUR. Ahora, en virtud de la Disposición Adicional I de la nueva Ley de asilo y protección subsidiaria se dispone la obligación de acordar, cada año, un número de personas que podrán ser objeto de reasentamiento. En aplicación de esta norma, se han aprobado los siguientes programas de reasentamiento: en 2011, se aprobó el reasentamiento de 80 personas de Túnez (Consejo de Ministros de octubre de 2011). En 2012: se aprobó el reasentamiento de 30 personas (Consejo de Ministros de 28 de diciembre de 2012). En 2013: se aprobó el reasentamiento de 100 personas (Consejo de Ministros de 13 de diciembre de 2013). En 2014: se aprobó el reasentamiento de 130 personas (Consejo de Ministros de 19 de diciembre de 2014): se espera que sean sirios acogidos en países limítrofes al conflicto. Y en 2015: 724 personas (Consejo de Ministros de 6 de noviembre de 2015). Ley 12/2009 de 30 de octubre reguladora del derecho de asilo y la protección subsidiaria. BOE núm. 263, de 31 de octubre de 2009.

53 Se establece que en dos años, desde la adopción de la Recomendación, se reasentará a 20.000 personas procedentes de lo que denomina "regiones prioritarias". Para determinar cuáles serán se tendrán en cuenta la situación de los países vecinos y los actuales flujos migratorios y, en particular, los Programas Regionales de Desarrollo y Protección establecidos en Oriente Próximo, norte de África y Cuerno de África (considerando 11 y art. 6). En 2005 se crearon Programas Piloto en Ucrania, Moldavia, Belarús y en Tanzania. En 2010, se prorrogaron y se establecieron dos nuevos: uno en el Cuerno de África (Kenia, Yemen y Djibouti) y en el Norte de África (Egipto, Libia y Tunez). En 2012, con objeto de ayudar a los países vecinos de Siria, se establece en Líbano, Jordania e Iraq. 
para todos los demás ${ }^{54}$. Salvo que la persona tenga algún familiar residiendo en un Estado miembro, en calidad de solicitante de protección o como beneficiario de la misma - en cuyo caso éste país sería el responsable de estudiar su solicitud en aras de proteger la unidad familiar-, el Estado miembro responsable será aquel que haya otorgado un visado o documento de residencia al demandante o aquel que haya permitido su entrada irregular ${ }^{55}$. Así, en el momento en el que las personas son interceptadas tratando de acceder de forma irregular o en el momento de presentar su solicitud de asilo, son tomados sus datos dactiloscópicos y enviados a una base informática a la que tienen acceso las autoridades de los Estados ${ }^{56}$. Cualquier intento de presentar la solicitud en otro Estado miembro, sería detectado con la mera comprobación del registro de sus huellas dactilares y sería devuelto al país responsable de su solicitud. Así las cosas, no debe de extrañar que, en los últimos años, los países situados en la frontera exterior de la Unión hayan sido responsables de evaluar la mayor parte de las solicitudes de protección que se presentaban en el conjunto del territorio comunitario ${ }^{57}$. Este sistema ha supuesto que no exista un

${ }^{54}$ Según el art. 3 del Reglamento Dublín III: "Los Estados miembros examinarán toda solicitud de protección internacional presentada por un nacional de un tercer país o un apátrida, ya sea en el territorio de cualquiera de ellos, incluida la frontera, o en las zonas de tránsito. La solicitud será examinada por un solo Estado miembro, que será aquel que los criterios mencionados en el capítulo III designen como responsable". Se trata, en definitiva, de impedir las llamadas "solicitudes múltiples", esto es, que un mismo solicitante de asilo presente una demanda de protección en más de un Estado miembro, habida cuenta que, al tener un sistema europeo común de asilo, todos deberían aplicar las mismas normas y ofrecer un sistema de acogida y procedimientos equivalentes. Sin embargo, la realidad dista mucho de esta máxima. Existe una gran discrepancia entre los Estados en cuanto al reconocimiento de protección respecto de personas de la misma nacionalidad. Así, por ejemplo, en 2014 las personas nacionales de Siria recibieron protección en un 95\% de los casos en Bulgaria, en un $69 \%$ en Hungría y un $0 \%$ en Croacia. En países como Reino Unido, Polonia o Alemania les concedieron el estatuto de persona refugiada, en cambio en Chipre, Malta, España, Países Bajos o Suecia se les concedió la protección subsidiaria.

EASO AnnualReport 2014, p. 44.

AIDA(Asylum Information Database): Common Asylum System at Turning Point: Refugees caught in Europe's Solidarity Crisis, Annual Report 2014/2015, pp. 18-19.

${ }^{55}$ Véase la jerarquía de criterios en el capítulo III del Reglamento.

En el caso de los/las menores no acompañados no se toma en consideración su entrada irregular sino si tienen algún familiar residiendo legalmente en un Estado miembro en cuyo caso éste sería el responsable, siempre que ello redunde en el interés superior del menor (art. 8).

56 Para la aplicación efectiva del Reglamento Dublín III, se requiere de una base central informatizada de datos dactiloscópicos que regula el Reglamento EURODAC. Según el art. 11 del citado Reglamento, se registrarán los siguientes datos: a) datos dactiloscópicos; b) Estado miembro de origen, lugar y fecha de la solicitud de protección internacional; en los casos a que se refiere el artículo 10, letra b), la fecha de solicitud será la introducida por el Estado miembro que trasladó al solicitante; c) sexo; d) número de referencia atribuido por el Estado miembro de origen; e) fecha de toma de las impresiones dactilares; f) fecha de transmisión de los datos al Sistema Central; g) identificación de usuario del operador; h) la fecha de llegada de la persona interesada tras un traslado exitoso, cuando proceda de conformidad con el artículo 10, letra a) o letra b); i) la fecha en que la persona interesada abandonó el territorio de los Estados miembros, cuando proceda de conformidad con el artículo 10, letra c); j) la fecha en que la persona interesada abandonó o fue expulsada del territorio de los Estados miembros, cuando proceda de conformidad con el artículo 10, letra d); k) la fecha de adopción de la decisión de examinar la solicitud, cuando proceda de conformidad con el artículo 10, letra e).

${ }^{57}$ En 2014, solo cinco Estados fueron responsables del $70 \%$ del total de solicitudes presentadas en 
reparto equitativo de la responsabilidad respecto de la determinación del estatuto de las personas necesitadas de protección en Europa y se encuentra en el origen de la situación de saturación de los sistemas de asilo de países como Grecia o Italia.

Grecia, que se haya en mitad de una crisis económica sin precedentes y que difícilmente puede atender a los colectivos más vulnerables de su población, empieza a dar muestras de su incapacidad para gestionar las solicitudes de protección y proporcionar las obligadas mínimas condiciones de acogida desde el año 2009 ${ }^{58}$. En la Sentencia del TEDH MSS contra Bélgica y Grecia, de 21 de enero de 2011, la Alta Instancia Judicial condena a Grecia por violar el artículo 3 del $\mathrm{CEDH}$, debido a las condiciones de "extrema pobreza" en la que abandonaba a los solicitantes de protección en su territorio ${ }^{59}$. Pero también condena a Bélgica por aplicar el Reglamento Dublín y trasladarlos allí, a sabiendas de que Grecia no podía cumplir con sus obligaciones, por lo que resulta responsable, de forma indirecta, de esas violaciones. La sentencia viene a quebrar el pilar básico en el que se sustenta el sistema Dublín, este es, la consideración de los Estados miembros como Estados seguros en materia de protección. A partir de este caso, se pone en cuestión que se apliquen los criterios jerárquicos de determinación de la responsabilidad de forma automática, pues según el Tribunal, se debe hacer un examen exhaustivo para comprobar que el Estado es seguro ${ }^{60}$. La sentencia es confirmada unos meses más tarde por el propio TJUE, en el asunto N.S. y Otros de 21 de diciembre de 2011. En él, se

toda la Unión. Solo Hungría recibió, en el primer trimestre del año 2015, 13 veces más solicitudes que en el mismo periodo del año 2014. Unión Europea. Eurostat. Asylum Quaterly Report, 2015.

${ }^{58}$ Tómese en consideración que según la Directiva 2013/33 sobre condiciones de acogida, las personas solicitantes de protección tienen derecho a unas "condiciones materiales de acogida" que según el art. $2 \mathrm{~g}$ ) incluyen: alojamiento, alimentación y vestido, proporcionados en especie o en forma de asignaciones financieras o de vales, o una combinación de las tres, y una asignación para gastos diarios.

${ }^{59}$ Caso MSS contra Bélgica y Grecia, 21.01.2011, § 252. En los parágrafos 254 y 255 puede leerse: "Constata que la situación en la que se encontró el demandante era de una particular gravedad. Explica haber vivido durante meses en la indigencia más absoluta, y no haber podido hacer frente a sus necesidades más elementales: alimentarse, lavarse y alojarse. A esto hay que añadir la permanente angustia de ser atacado o robado así como la ausencia total de perspectiva de mejorar. Es para terminar con esta situación de precariedad y angustia que intentó, en varias ocasiones, abandonar Grecia". "El Tribunal observa en los comentarios del Comisario de Derechos Humanos del Consejo de Europa y del ACNUR, así como en los informes de las organizaciones no gubernamentales (§ 160) que la situación descrita por el demandante es un fenómeno a gran escala y corresponde a la realidad de un gran número de solicitantes de asilo con el mismo perfil que el demandante. Por esta razón, el Tribunal no duda de las alegaciones de éste". Nótese que según el Tribunal, el artículo 3 del Convenio no implica una obligación para el Estado de otorgar asilo o ciertos estándares de vida (que sí forman parte del Derecho vinculante de la Unión Europea: véase nota ${ }^{\circ}$ 55), pero sí protege valores esenciales, lo que llama "condiciones de vida decentes". (MSS contra Bélgica y Grecia, § 250).

${ }^{60}$ Así establece que: “(...) dependía de las autoridades belgas, dada la situación descrita, no sólo asumir que el demandante recibiría un trato conforme a las exigencias del Convenio, sino por el contrario investigar previamente la manera en que las autoridades griegas aplican la legislación en materia de asilo en la práctica. Al hacerlo, podrían haber constatado que el riesgo invocado por el demandante era suficientemente real e individualizado para depender del artículo 3" (MSS contra Bélgica y Grecia, § 359). 
dispone que no se podrá trasladara un solicitante de asilo al Estado miembro responsable "cuando no se puedan ignorar que las deficiencias sistemáticas del procedimiento de asilo en ese Estado miembro constituyan motivos serios y acreditados para creer que el solicitante correrá un riesgo real de ser sometido a tratos inhumanos o degradantes" ${ }^{\prime 61}$. Esta sentencia ha provocado la enmienda del Reglamento Dublín III que ya incorpora esta premisa en su art. 3.2 ${ }^{62}$. A partir de la fecha de la sentencia, son suspendidos los traslados a Grecia ${ }^{63}$.

Ya tenemos también una STEDH que condena la devolución de solicitantes de protección a Italia, caso Tarakhel contra Suiza de 4 de noviembre de 2014. En este caso, la Alta Instancia judicial ha decidido que devolver a Italia a la familia en respuesta a las exigencias del sistema de Dublín, sin que Suiza obtuviera garantías individuales de que las autoridades italianas iban a hacerse cargo de los solicitantes de una manera adecuada a la edad de los hijos, y que la unidad de la familia iba a ser respetada, y sin garantías de que la familia se beneficiaría de unas condiciones de acogida apropiadas, representa una violación del artículo 3 de la Convención que protege de tratos inhumanos y degradantes. Debido a las importantes deficiencias detectadas en el sistema italiano de acogida, Tribunal Europeo ha considerado que, en este caso como en los demás, la seguridad de los solicitantes no puede darse por sentada. De nuevo, el Tribunal recuerda que los Estados miembros, antes de trasladar a los solicitantes de protección por los procedimientos previstos en el sistema de Dublín, deben obtener garantías individuales de que sus derechos serán respetados en el país miembro de destino (caso Tarakhel contra Suiza, § 120).

Ante la necesidad inmediata de ayudar a los Estados más afectados por la crisis a cumplir con sus obligaciones en materia de protección internacional, las Instituciones de la Unión adoptan medidas que inciden en lo que podemos denominar "solidaridad financiera", esto es, ayuda de emergencia de carácter económico, así como "solidaridad operativa", es decir, medidas de

${ }^{61}$ TJUE: asunto NS y Otros, 21 de diciembre de 2011 (C411/10 y C493/10). ECLI:EU:C:2011:865.

${ }^{62}$ Art. 3.2 del Reglamento Dublín III: “(...) Cuando sea imposible trasladar a un solicitante al Estado miembro que se haya designado en primer lugar como responsable, debido a que hay razones fundadas para temer que existen deficiencias sistemáticas en el procedimiento de asilo y en las condiciones de acogida de los solicitantes en ese Estado miembro que implican un peligro de trato inhumano o degradante, en el sentido del artículo 4 de la Carta de los Derechos Fundamentales de la Unión Europea, el Estado miembro encargado de la determinación seguirá examinando los criterios fijados en el capítulo III para decidir si otro Estado miembro puede ser designado como responsable (...)".

${ }^{63}$ La doctrina del Tribunal ha sido confirmada en el caso Sharifi y Otros contra Italia y Grecia, de 21 de octubre de 2014, donde la Alta Instancia Judicial recuerda que Estados que tienen intención de trasladar una persona a otro país designado por las reglas de Dublín como responsable de examinar la solicitud de asilo, antes deben asegurarse que el país de destino pueda ofrecer las garantías suficientes para que la persona no sea expulsada a su país de origen sin una valoración de los riesgos que eso comportaría. En este caso, Italia tenía que haber examinado casos por caso las circunstancias de los recurrentes y tenía que haberse asegurado de la manera en la que las autoridades griegas aplican en la práctica la legislación en materia de protección internacional.

Araucaria. Revista Iberoamericana de Filosofía, Política y Humanidades, año 18, n 36. Segundo semestre de 2016. Pp. 339-372. ISSN 1575-6823 e-ISSN 2340-2199 doi: 10.12795/araucaria.2016.i36.15 
soporte práctico como la activación de equipos de apoyo a la gestión de la migración en los "puntos críticos" (hotspots) seleccionados en Grecia e Italia o del mecanismo de protección civil para Serbia, Eslovenia y Croacia ${ }^{64}$. Estas medidas podían ayudar en la agilización de la tramitación de las solicitudes, así como de los retornos o en la creación de mejores infraestructuras para dar acogida a las personas, sin embargo, las llegadas son de tal magnitud que se hacía imperioso proceder a la adopción de una auténtica medida de solidaridad intra-comunitaria. Un reparto equitativo de la responsabilidad sólo podía lograrse con la reubicación de solicitantes de protección internacional hacia el resto de Estados miembros, una medida contraria a la lógica del sistema Dublín y que viene a demostrar la imperiosa necesidad de su reforma.

El sistema europeo común de asilo ya dispone de una norma para atender las situaciones de afluencia masiva de personas desplazadas, en la Directiva 2001/55, en la que se garantiza a las mismas protección inmediata y se establece una distribución de las mismas entre los Estados miembros ${ }^{65}$. Este procedimiento puede activarse por decisión del Consejo por mayoría cualificada, por lo que no sería objeto de veto, y resulta vinculante incluso para aquellos Estados miembros que hubieran votado en contra ${ }^{66}$. Esta Directiva resulta de gran relevancia porque consigue el suficiente consenso en torno a la idea de que la decisión de acogida en caso de afluencias masivas debe ser vinculante, pero no establece un criterio de reparto de las personas que,

\footnotetext{
${ }^{64}$ Se ha alcanzado el compromiso financiero de 9.200 millones de euros para atender la llamada “crisis de refugiados" en 2015-2016. Por lo que respecta a los "puntos críticos", se trata de equipo coordinados por la Comisión, que ayudan en la tramitación conjunta de solicitudes, incluido el registro y la toma de impresiones dactilares de las personas, así como el retorno de aquellos que no tengan derecho a la protección y en los que colaboran la EASO, Frontex y Europol. Se han seleccionado 6 hotspot en Italia (Lampedusa, Pozzallo, Porte Empedocle, Augusta, Taranto y Trapani, si bien solo están operativos los de Lampedusa y Trapani); y en 5 en Grecia (Lesvos, Chios, Samos, Leros y Kos, si bien solo está operativo el de Lesvos). En cuanto al mecanismo de protección civil activado para Grecia, Serbia, Eslovenia y Croacia, se han movilizado diversos tipos de ayudas en especie, incluidos equipos y material, suministros médicos y otros artículos no alimentarios, además de expertos.

Pueden verse estas medidas actualizadas a 19 de enero de 2016 en Comisión Europea. Situación actual: medidas para hacer frente a la crisis de los refugiados. Comunicado de Prensa, 19.01.2016, disponible en: http://europa.eu/rapid/press-release_IP-15-6134_es.htm

${ }^{65}$ Según el art. 2 a) de la Directiva 2001/55, se entiende "Protección Temporal": un procedimiento de carácter excepcional por el que, en caso de afluencia masiva o inminencia de afluencia masiva de personas desplazadas procedentes de terceros países que no puedan volver a entrar en su país de origen, se garantiza a las mismas protección inmediata y de carácter temporal, en especial si el sistema de asilo también corre el riesgo de no poder gestionar este flujo de personas sin efectos contrarios a su buen funcionamiento, al interés de las personas afectadas y al de las otras personas que soliciten protección.

${ }^{66}$ El art. 5.1 de la Directiva dispone que "la existencia de una afluencia masiva de personas desplazadas se constatará por una decisión del Consejo adoptada por mayoría cualificada a propuesta de la Comisión, que examinará igualmente cualquier solicitud de un Estado miembro de que presente una propuesta al Consejo". Esta decisión sería obligatoria. Así, según el art. 5.3: "La decisión del Consejo determinará la aplicación en todos los Estados miembros de la protección temporal, respecto de las personas desplazadas a las que se refiera, de conformidad con las disposiciones de la presente Directiva”. La cursiva es la autora.
} 
finalmente, quedarían a merced de la capacidad de recepción que determinara cada Estado. Si a este inconveniente le sumamos que incorpora un concepto de personas beneficiaria de protección temporal bastante amplio que hoy día superaría los colectivos que la Unión ha determinado que son beneficiarios de la protección internacional ${ }^{67}$, que además le otorga un estatuto bastante garantista y que el sistema está sometido a doble voluntariedad (a la voluntad de acogida del Estado miembro y al consentimiento del beneficiario/a)no resulta extraño que este instrumento no se haya utilizado nunca.

En su lugar y ante la evidencia de que nos hallamos ante una "situación de emergencia caracterizada por una afluencia repentina de nacionales de terceros Estados", se decide activar el mecanismo de emergencia previsto en el artículo 78.3 del TFUE ${ }^{68}$, y con él se adoptan medidas "provisionales" como son, en primer lugar, el establecimiento de una excepción temporal a la aplicación del artículo 13.1 del Reglamento Dublín III (entrada irregular) y, en segundo lugar, la reubicación de esas personas para que otro Estado miembro proceda al examen de su solicitud de protección internacional. Todo ello de conformidad con el artículo 80 TFUE, que exige que las políticas de la Unión en el ámbito de los controles fronterizos, el asilo y la inmigración y su aplicación -incluida las medidas adoptadas en caso de "situación de emergencia"- se rijan por el principio de "solidaridad" y "reparto equitativo de la responsabilidad". Así, en virtud de la Decisión 2015/1523 del Consejo, de 14 de septiembre de 2015 se decide reubicar a 40.000 personas en los próximos dos años, es decir, hasta el 17 de septiembre de $2017^{69}$ y en aplicación de la Decisión 2015/1601 del Consejo, de 22 de septiembre de 2015, se reubicarán 120.000 personas en los próximos dos años, por tanto, hasta el 26 de septiembre de $2017^{70}$.

67 Según el art. 2. c): se entiende por personas desplazadas "los nacionales de un tercer país o apátridas que hayan debido abandonar su país o región de origen, o que hayan sido evacuados, en particular respondiendo al llamamiento de organizaciones internacionales, y cuyo regreso en condiciones seguras y duraderas sea imposible debido a la situación existente en ese país, que puedan eventualmente caer dentro del ámbito de aplicación del artículo 1A de la Convención de Ginebra u otros instrumentos internacionales o nacionales de protección internacional, y en particular: i) las personas que hayan huido de zonas de conflicto armado o de violencia permanente; ii) las personas que hayan estado o estén en peligro grave de verse expuestas a una violación sistemática o generalizada de los derechos humanos".

${ }^{68}$ Art. 78.3 TFUE: "Si uno o varios Estados miembros se enfrentan a una situación de emergencia caracterizada por la afluencia repentina de nacionales de terceros países, el Consejo podrá adoptar, a propuesta de la Comisión, medidas provisionales en beneficio de los Estados miembros afectados. El Consejo se pronunciará previa consulta al Parlamento Europeo". El Parlamento Europeo vota a favor en una sesión de urgencia, el día 17 de septiembre de 2015.

${ }^{69}$ Decisión 2015/1523 del Consejo, de 14 de septiembre de 2015 relativa al establecimiento de medidas provisionales en el ámbito de la protección internacional en favor de Italia y Grecia. DO L 239, 15.09.2015. En adelante, Decisión 2015/1523.

${ }^{70}$ Decisión 2015/1601 del Consejo, de 22 de septiembre de 2015 por la que se establecen medidas provisionales en el ámbito de la protección internacional en beneficio de Italia y Grecia. DO L 248, 24.09.2015. En adelante, Decisión 2015/1601. 
En total, 160.000 personas se beneficiarán de esta medida y, como contrapartida, Italia y Grecia han presentado unos "planes de trabajo" con medidas oportunas en el ámbito del asilo, primera acogida y retorno, con el fin de mejorar la capacidad, la calidad y la eficiencia de sus sistemas de asilo (art. 8 de la Decisión 2015/1523) el 16 de septiembre de 2015 y unas "hojas de ruta" actualizadas a 26 de octubre de 2015 (art. 8 de la Decisión 2015/1601). Finalmente, Hungría rechaza ser uno de los países designados y vota en contra de la decisión, junto con la República Checa, Eslovaquia y Rumanía ${ }^{71}$. No obstante, todos están obligados a aceptar la reubicación y, de hecho, la norma dispone - esta es la gran novedad- una clave de reparto vinculante y unos anexos con el número de beneficiarios que corresponde a cada uno de los países ${ }^{72}$. Se supera así, el gran escollo de la Directiva 2001/55 que disponía también una obligación de acogida, pero que carecía de un sistema para proceder al reparto de personas de forma automática.

71 La Decisión 2015/1523 se adopta por unanimidad en el Consejo, sin embargo, la Decisión 2015/1601 se adopta con los votos en contra de Eslovaquia, República Checa y Hungría; así como con la abstención de Dinamarca. En la propuesta de la Comisión, sí estaba previsto incluir a Hungría entre los Estados afectados ya que: "El cambio en la composición demográfica de las nacionalidades que están llegando a Hungría a través de los Balcanes Occidentales desde principios de 2015 y el aumento significativo de 3 Sesión no 3405 del Consejo de Justicia y Asuntos de Interior, documento 11097/15. ES 3 ES las llegadas durante los meses de verano apuntan a una nueva situación de emergencia que se corresponde con los criterios previstos en el artículo 78, apartado 3. El aumento significativo del número de nacionales sirios que llegan a través de esta ruta sugiere que es más que probable que los flujos de personas que están llegando estén necesitados de protección internacional. El aumento exponencial durante un breve período de tiempo también ha impedido que Hungría despliegue recursos suficientes para disponer de una capacidad de acogida y unos procedimientos de asilo que respondan a las necesidades actuales. Por consiguiente, la Comisión ha concedido a Hungría ayuda de emergencia en el marco del Fondo de Asilo, Migración e Integración y del Fondo de Seguridad Interior. A pesar de la acuciante necesidad de asistencia, prevalecen los desplazamientos posteriores hacia Austria y Alemania, y Hungría se ha convertido en un país de tránsito para la mayoría de los inmigrantes, que prefieren no seguir adelante con su solicitud o no solicitar protección internacional en Hungría. Las mismas tendencias migratorias se observan tanto en Grecia como en Italia. Así pues, se justifica la adopción de una nueva medida de reubicación desde estos tres Estados miembros, no solo por la permanente presión migratoria a la que se ven sometidos, sino también porque, debido a las difíciles circunstancias en las que se encuentran al llegar a Italia, Grecia y Hungría, la mayoría de las personas que entran por las fronteras exteriores de la UE buscan protección en otros lugares". Propuesta de Decisión del Consejo por la que se establecen medidas provisionales en el ámbito de la protección internacional en beneficio de Italia, Grecia y Hungría. COM (2015) 451 final, p. 3.

España ha sostenido que la reubicación debía ser de carácter voluntario y no "impuesta” dado su potencial efecto llamada y el consecuente efecto desestabilizador en los países de origen y tránsito. Propuesta de Decisión del Consejo relativa al establecimiento de medidas provisionales en el ámbito de la protección internacional a favor de Italia y Grecia. 8 de julio de 2015. JAI AAII Decisión Reubicación.

${ }^{72}$ Se han determinado cuatro variables para disponer el reparto de personas entre los Estados: La población: ponderación 40\%; el PIB total: ponderación del 40\%; el promedio de solicitudes de asilo en los 5 años anteriores por millón de habitantes, con un límite máximo del $30 \%$ de la población y del PIB-ponderación del 10\%; la tasa de desempleo: límite máximo de 30\% de población y del PIB, ponderación del 10\%. En virtud de esta variable, a España le corresponde acoger: 1896 personas desde Italia y 6127 desde Grecia. 
Se dispone, pues, de una decisión obligatoria de reubicación, un año para reubicar una cantidad de personas y otro año para el resto, así como un presupuesto específico de FAMI que financia con 6000 euros cada persona reubicada y 500 para Italia y Grecia con objeto de costear el traslado. Tratándose de una supuesta medida de "emergencia" que tiene como beneficiarios personas vulnerabilizadas, como son las personas solicitantes de protección internacional, que van a ser reubicadas precisamente porque en esos países no se les puede garantizar una gestión adecuada de su solicitud ni condiciones de acogida dignas, no parece que el plazo de dos años sea un lapso temporal "razonable"73. El número de personas reubicadas a 10 de enero de 2016 (249

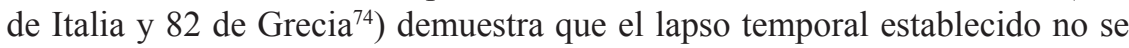
compadece, en absoluto, con una medida con supuesto carácter de emergencia y que existe una falta absoluta de voluntad política al respecto que debiera haber implicado ya el inicio del procedimiento de incumplimiento por parte de la Comisión.

El escollo para tan insolidaria falta de diligencia no debe hallarse en las personas seleccionadas para ser reubicadas, pues no serán todas las que se han registrado en Grecia o Italia como demandantes de protección internacional sino que se lleva a cabo una criba previa. Serán reubicadas solo aquellas que las Decisiones han designado como personas con "necesidad manifiesta de protección", esto es, los solicitantes de nacionalidades para las que se haya adoptado una proporción de al menos el $75 \%$ de resoluciones de concesión de protección internacional en primera instancia, según los últimos datos trimestrales actualizados de Eurostat, (art. 3.2), es decir, las personas nacionales de Eritrea, Iraq, República Centro Africana y Siria. Una vez realizado el traslado, los Estados miembros de reubicación procederán a conceder el estatuto de refugiado/a o el de beneficiario/a de protección subsidiaria según los casos, pero ya hay una "presunción de reconocimiento positivo" a favor de estos colectivos. Además, aunque a los Estados se les impone un número y un plazo de tiempo para reubicar, lo cierto es que no se les impone una lista de personas con nombre y apellidos sino que los funcionarios de enlace de los Estados miembros junto con los de Italia, Grecia y la EASO determinan qué solicitantes concretos pueden reubicar -dando prioridad a los más vulnerables y teniendo en cuenta sus competencias lingüísticas y otras indicaciones, como lazos

${ }^{73}$ En el considerando 17 de la Decisión 2015/1523 y en el 22 de la Decisión 2015/1601, se considera que sí se trata de un plazo razonable para que la medida tenga un impacto real para ayudar a Italia y Grecia.

${ }^{74}$ Bélgica: 6 (Grecia); Finlandia: 96 (Italia) y 24 (Grecia); Francia: 19 (Italia); Alemania: 11 (Italia) y 10 (Grecia); Lituania: 4 (Grecia); Luxemburgo: 30 (Grecia); Países Bajos: 50 (Italia); Portugal: 10 (Italia) y 14 (Grecia); España: 18 (Italia); Suecia: 39 (Italia). Aún hay 7 Estados que ni siquiera han comunicado el número de solicitantes que pueden reubicar a pesar de la obligación al respecto del art. 5 de ambas Decisiones. Comisión Europea. Comunicado de Prensa: Situación actual de las medidas para hacer frente a la crisis de refugiados, 16.01.2016.

Araucaria. Revista Iberoamericana de Filosofía, Política y Humanidades, año 18, no 36. Segundo semestre de 2016. Pp. 339-372. ISSN 1575-6823 e-ISSN 2340-2199 doi: 10.12795/araucaria.2016.i36.15 
familiares, culturales o sociales que puedan facilitar su integración (criterio de selección incluido a instancias del Parlamento Europeo ${ }^{75}$ ) - y aprueban la lista final (art. 5.4 de las Decisiones). En todo este proceso queda claro que las personas reubicadas son las que no tienen derecho a elegir el Estado responsable de su acogida. La voluntad de la persona demandante de protección no tiene cabida en la ecuación - motivo por el cual Dinamarca se abstuvo en la votación en el Consejo-, en línea con la doctrina asentada al respecto por el Reglamento Dublín III que no permite al demandante la elección del foro y que ya es un dogma en el sistema europeo común de asilo.

Se pretende que esta respuesta de emergencia ante crisis relacionadas con las afluencias masivas se incorpore al sistema de forma permanente. Para ello, se ha publicado una Propuesta de la Comisión que establece un mecanismo permanente de reubicación de crisis, como nueva enmienda al Reglamento Dublín III y que se activaría siempre que la Comisión decida que se ha está produciendo una "afluencia masiva y desproporcionada de nacionales de terceros países que plantee dificultades para los sistemas de protección" y no haya objeción del Consejo, ni del Parlamento Europeo en el plazo de un mes desde la notificación de la misma ${ }^{76}$.

75 Parlamento Europeo. Informe sobre la Propuesta de Decisión del Consejo relativa al establecimiento de medidas provisionales en el ámbito de la protección internacional en favor de Italia y Grecia. Comisión de libertades Civiles, Justicia y Asuntos de Interior. A8/0245/2015, 28.07.2015.

${ }^{76}$ Comisión Europea. Propuesta de Reglamento del Parlamento Europeo y del Consejo por el que se establece un mecanismo de reubicación de crisis y se modifica el Reglamento (UE) n ${ }^{\circ}$ 604/2013 del Parlamento Europeo y del Consejo, de 26 de junio de 2013, por el que se establecen los criterios y mecanismos de determinación del Estado miembro responsable del examen de una solicitud de protección internacional presentada en uno de los Estados miembros por un nacional de un tercer país o un apátrida. COM (2015) 450 final, 09.09.2015. Se tendrá que adoptar de acuerdo con el procedimiento legislativo ordinario, por tanto, en codecisión con el Parlamento Europeo a diferencia de las Decisiones de reubicación que solo necesitaban la consulta. En estos momentos, continúan los debates en el seno del Consejo. En la reunión del 1 de diciembre de 2015, algunas delegaciones formularon reservas generales y reiteraron sus posiciones en el sentido de que sería preferible evaluar el funcionamiento de los mecanismos de reubicación de emergencia temporal, adoptados por el Consejo el 14 y 22 de septiembre, antes de seguir el debate de la propuesta sobre el mecanismo de crisis en materia de reubicación. Opinan que es preciso tratar con urgencia las carencias en la aplicación de las decisiones sobre reubicación, incluidos el funcionamiento de los puntos críticos y la prevención de desplazamientos secundarios. Algunas delegaciones reiteraron la necesidad de situar el estudio de la actual propuesta en un contexto más amplio y en el marco de la evaluación en curso del Reglamento "Dublín” y su posterior reforma anunciada por la Comisión para marzo de 2016. No obstante, otras delegaciones apoyaron a la Presidencia al subrayar la importancia de continuar los debates para buscar un reparto más equitativo de la carga entre Estados miembros. Consejo de la Unión Europea. Expediente Interinstitucional 2015/0208 (COD), ASIM 157, CODEC 1578, para. 3. 


\section{Conclusiones}

I. La intensificación de las corrientes migratorias hacia Europa, principalmente por vía marítima, como consecuencia de los conflictos de carácter económico, social y político en África y Medio Oriente -especialmente en Siria- ha provocado que nos hallemos ante la que se ha denominado la crisis humanitaria más importante de nuestra era. Desbordada la capacidad de acogida de los países vecinos a las zonas de conflicto -Turquía, Líbano, Jordania-, se han incrementado las afluencias hacia Europa y con ellas la trágica y constante pérdida de vidas humanas en el mar. Tarde y de forma descoordinada, la Unión Europea reacciona adoptando medidas que inciden en la doctrina asentada de contención de flujos fuera de territorio europeo, el retorno y la lucha contra la inmigración irregular, y solo en menor medida se adoptan decisiones en el marco de la llamada "solidaridad internacional" (reparto de la responsabilidad en materia de personas refugiadas con terceros países afectados), así como entre los socios comunitarios. En el marco de ambos tipos de medidas, se han puesto en marcha actuaciones insólitas hasta el momento y que son las que se han analizado en este estudio. En el ámbito de la lucha contra la inmigración irregular, se ha activado una operación militar de gestión de crisis para luchar contra el tráfico ilícito de personas. Y en el marco de las medidas que inciden en el reparto de la responsabilidad en materia de personas refugiadas, se ha decidido la reubicación de aquellas manifiestamente necesitadas de protección desde Grecia e Italia al resto de Estados miembros de la Unión.

II. Ante la ausencia de cauces legales y seguros para acceder a la protección internacional desde fuera de Europa, muchas personas que huyen de la persecución o los daños graves -al igual que otros migrantes- se ven obligadas a acudir a las redes delictivas de traficantes para llegar a territorio europeo y así poder presentar su solicitud de protección. Precisamente, la lucha contra este medio de entrada irregular a Europa ha obtenido un inusitado protagonismo en mitad de la crisis migratoria del Mediterráneo. Partiendo de la consideración de estas actividades como una amenaza a la seguridad de la Unión y su desmantelamiento como vía para evitar la pérdida de vidas en el mar, se han adoptado medidas de carácter militar insólitas en este campo.

III. Europa ha declarado "la guerra contra los traficantes" y para ello ha activado una operación militar de gestión de crisis (EUNAVFOR MED Sophia), por Decisión PESC 2015/778 del Consejo de 18 de mayo de 2015. Esta operación está diseñada para desarrollarse en tres fases, de las que ya se han activado las dos primeras. En virtud de la primera fase, se permite detectar y seguir las redes de migraciones mediante la recopilación de información y el patrullaje en alta mar. En la segunda fase, es posible visitar, registrar, apresar y desviar los buques sospechosos, en alta mar y en las aguas interiores del Estado 
ribereño con su consentimiento o sin él, de conformidad con una decisión del Consejo de Seguridad (segunda fase activada el 7 de octubre de 2015). Y, en una última fase, de acuerdo con cualquier Resolución del Consejo de Seguridad o el consentimiento del Estado ribereño, adoptar todas las medidas necesarias incluso la eliminación o inutilización, contra un buque que se sospeche se utiliza contra el tráfico ilícito o la trata de seres humanos, en el territorio de dicho Estado.

IV. Con objeto de dar cobertura jurídica a la segunda fase, el Consejo de Seguridad de Naciones Unidas adopta la Resolución 2240 (2015) de 9 de octubre de 2015 que supone una excepción a la necesidad de contar con el consentimiento del Estado del pabellón para determinadas actuaciones en alta mar, concretamente, frente a las costas de Libia. Así, la Resolución autoriza, durante un año, a "inspeccionar" los buques en alta mar cuando se tengan motivos razonables para creer que han sido, están siendo o serán utilizados inminentemente para el tráfico de inmigrantes o la trata de personas desde Libia "aún sin el consentimiento del Estado del pabellón", siempre y cuando hayan intentado de buena fe obtener el consentimiento de ese Estado y le mantengan informado. Cuando se confirme que los barcos están siendo utilizados para el tráfico de migrantes o la trata de personas se autoriza a "apresar" los buques inspeccionados. Y tanto para la inspección como para el apresamiento, se autoriza a "emplear todas las medidas que dicten las circunstancias" -lo que viene a incluir el uso de la fuerza- solo en alta mar frente a las costas de Libia (no en sus aguas interiores ni en su territorio, a diferencia de lo que pretende la tercera fase de la operación EUNAVFOR MED Sophia).

V. Con independencia de los interrogantes jurídicos que suscitan la Decisión PESC y la Resolución del Consejo de Seguridad y de la manifiesta inutilidad de las mismas para la finalidad perseguida, consideramos que ambas decisiones tienen, además, tres importantes consecuencias en lo que a los derechos de las personas refugiadas y beneficiarias de protección subsidiaria se refiere. De entrada, parten de la base de que las tragedias que se producen en el Mediterráneo son consecuencia del tráfico ilícito (o de la trata de personas, obviando por completo -no sin interés- que este fenómeno no suele utilizar estos cauces para trasladar a los seres humanos que serán tratados en otros países) y no reconocen que la utilización de las mafias es solo un síntoma más del problema. No se mencionan las causas que realmente empujan a estas personas a hacer uso de estos medios ilegales que, sobre todo, ponen en peligro su vida y seguridad. En segundo lugar, en base a una noción expandida de seguridad integral, se adoptan medidas represivas, policiales y militares que criminalizan a las personas migrantes y refugiadas y que no están exentas de riesgos para sus vidas. La criminalización de una crisis de carácter claramente humanitario supone una peligrosa vuelta de tuerca del proceso de securitización 
que ha caracterizado el nacimiento y desarrollo de la Política europea de asilo y migración. Y, por último, no se explica cómo se va a hacer compatible el mandato de la operación con el derecho a solicitar protección internacional que tienen estas personas o con el efectivo cumplimiento del principio de no devolución que ni siquiera nombra. La Resolución del Consejo de Seguridad reconoce que entre los migrantes sujetos a tráfico puede haber personas que "respondan a la definición de refugiado" e incluso insiste en la obligación de tratar a las personas migrantes con humanidad y dignidad y en estricto cumplimiento de las obligaciones derivadas del Derecho Internacional de los Derechos Humanos y el Derecho Internacional de las Personas Refugiadas. Por tanto, la acción prioritaria ha de ser desembarcar a estas personas en un "lugar seguro" que no solo debe implicar la protección frente a un posible peligro físico sino que también debe tener en cuenta la dimensión de los derechos fundamentales en cuanto al lugar del desembarco. En las circunstancias actuales, se debe disponer, de forma expresa, el desembarco en un puerto seguro europeo, con objeto de que puedan ejercer su derecho a solicitar protección internacional, así como la prohibición de su devolución tal y como ha sido definido en la CDFUE, la jurisprudencia del TJUE y del TEDH, según la cual, ninguna persona puede ser desembarcada en un país, forzada a entrar, conducida o entregada de algún otro modo a sus autoridades, incumpliendo el principio de no devolución cuando, entre otros supuestos, exista un riesgo grave de que se vea expuesta a sufrir pena de muerte, tortura, persecución o cualquier otra pena o trato inhumano o degradante o cuando su vida o su libertad estén amenazadas por motivos de raza, religión, nacionalidad, pertenencia a determinado grupo social u opiniones políticas o cuando exista un riesgo grave de que sea expulsada, trasladada o extraditada a otro país incumpliendo este principio. Concretamente, la proscripción de la tortura y las penas o tratos inhumanos o degradantes es de carácter absoluto y no exime su cumplimiento el hecho de que nos hallemos ante afluencias masivas.

VI. Lo que el tráfico ilícito de migrantes y la pérdida de vidas en el mar ha puesto sobre la mesa es la necesidad de establecer vías de acceso efectivo, seguro y legal a territorio europeo para aquellos/as en necesidad de protección. El reasentamiento no puede ser la única opción a la vista de la saturación de la capacidad de acogida de los países vecinos de las zonas en conflicto y menos aún con una Recomendación UE que solo dispone 20.000 plazas para el conjunto de la Unión. Si el objetivo es que las redes de tráfico pierdan su razón de ser y las personas no necesiten poner en tan grave peligro sus vidas para cruzar el Mediterráneo, se deben arbitrar otras opciones en Derecho, como visados humanitarios, ampliar los supuestos de reagrupación familiar, así como especialmente permitir la solicitud de protección internacional en las embajadas de los Estados miembros en el exterior; cuestiones no reguladas en 
el sistema europeo común de asilo y que no ha merecido apenas mención en las medidas adoptadas para atajar esta crisis.

VII. Otra de las medidas novedosas que se han adoptado ha sido la decisión de reubicar a aquellas personas con manifiesta necesidad de protección desde Grecia e Italia al resto de países miembros. Se trata de una importante medida que coadyuva a incorporar un auténtico reparto de la responsabilidad en materia de personas refugiadas ajeno a la dinámica impuesta por el sistema Dublín. El Reglamento Dublín III y la aplicación de sus criterios jerarquizados ha supuesto que los Estados fronterizos del Mediterráneo sean responsables del examen de toda demanda de protección que se presenta en su territorio o las de aquellas personas que llegan al mismo de forma irregular. Ante el incremento de los flujos a través de esta frontera, se ha producido el colapso de algunos sistemas que como el griego no solo no cumplían con las obligaciones básicas que el sistema europeo común de asilo establece sino que han llegado a abandonar a las personas solicitantes de asilo en situación de extrema pobreza, lo que ha sido sancionado por el TEDH (caso Mss contra Bélgica y Grecia) y el TJUE (asunto N.S y Otros). Ante la evidencia de que tanto Grecia como Italia resultaban incapaces de gestionar adecuadamente las solicitudes de protección pendientes, se decide activar el mecanismo de emergencia previsto en el artículo 78.3 TFUE y con él se adoptan "medidas provisionales" como son: en primer lugar, el establecimiento de una excepción temporal a la aplicación del artículo 13.1 del Reglamento Dublín III (entrada irregular) y, en segundo lugar, la reubicación de esas personas para que otro Estado miembro proceda al examen de su solicitud de protección internacional. Todo ello de conformidad con el artículo 80 TFUE, que exige que las políticas de la Unión en el ámbito de los controles fronterizos, el asilo y la inmigración y su aplicación -incluida las medidas adoptadas en caso de "situación de emergencia"- se rijan por el principio de "solidaridad" y "reparto equitativo de la responsabilidad". Así, en virtud de la Decisión 2015/1523 del Consejo, de 14 de septiembre de 2015 se decide reubicar a 40.000 personas en los próximos dos años, es decir, hasta el 17 de septiembre de 2017 y en aplicación de la Decisión 2015/1601 del Consejo, de 22 de septiembre de 2015, se reubicarán 120.000 personas en los próximos dos años, por tanto, hasta el 26 de septiembre de 2017.

VIII. Con estas dos Decisiones, se ha logrado incorporar al sistema una obligación de reubicación que será vinculante para todos los Estados, así como una clave de reparto, en aplicación de la cual, se establece qué número de personas reubicadas le corresponden a cada uno de ellos. Se supera así el gran escollo de la Directiva 2001/55 que aunque también disponía una obligación de acogida en casos de afluencia masiva, carecía de un sistema para proceder a la distribución de las personas de forma automática. 
IX. El problema es que dispone un lapso temporal de dos años para llevar a cabo las reubicaciones, el cual, habida cuenta de la situación de vulnerabilidad en la que se encuentran estas personas en Grecia e Italia, no parece razonable. Hasta la fecha se han reubicado 249 personas desde Italia y 82 desde Grecia, lo cual demuestra que tamaño ámbito de aplicación temporal se compadece mal con una supuesta medida de emergencia y que existe una falta absoluta de voluntad política al respecto de las reubicaciones que debiera haber implicado ya la activación del procedimiento de incumplimiento. Y esto es así, a pesar de que las personas que se han de reubicar no son todas las registradas en Grecia e Italia sino aquellas con "manifiesta necesidad de protección", término que se identifica, según las Decisiones de reubicación, con las personas cuyas nacionalidades hubieran obtenido protección internacional en un $75 \%$ de los casos en todo el territorio de la Unión, en atención a los últimos datos trimestrales de Eurostat (Eritrea, Iraq, República Centro Africana y Siria). Es decir, que se reubicarán las personas respecto de las cuales existe ya una presunción de reconocimiento positivo a su favor, lo que implicará que los procedimientos para conceder el estatuto de refugiado/a o beneficiario/a de protección subsidiaria serán rápidos y poco costosos. Además, no se les impone una lista de personas sino que los funcionarios de enlace de los Estados miembros junto con los de Italia, Grecia y la EASO determinan qué solicitantes concretos pueden reubicar -dando prioridad a los más vulnerables y teniendo en cuenta sus competencias lingüísticas y otras indicaciones, como lazos familiares, culturales o sociales que puedan facilitar su integración- y aprueban la lista final. En todo este proceso queda claro que las personas reubicadas son las que no tienen derecho a elegir el Estado responsable de su acogida. La voluntad de la persona demandante de protección no tiene cabida en la ecuación, en línea con la doctrina asentada al respecto por el Reglamento Dublín III que no permite al demandante la elección del foro y que ya es un dogma en el sistema europeo común de asilo.

$\mathrm{X}$. En todo caso, esta crisis nos demuestra que no se puede actuar ex post conflicto y con carácter ad hoc. Mientras la sociedad internacional institucionalizada no sea capaz de atajar las causas que se encuentran en el origen de los desplazamientos de población, las afluencias de personas necesitadas de protección, masivas o no, van a continuar produciéndose y no se puede hacer responsables de las mismas, en exclusiva, a los Estados europeos fronterizos. El sistema europeo común de asilo necesita disponer de un mecanismo de reparto de la responsabilidad en materia de refugiados de forma permanente y que no esté sujeto a situaciones de emergencia. Ello requiere cambiar los criterios de asignación de la responsabilidad en el estudio de las demandas de protección internacional para dar menos peso a la entrada irregular y más a los criterios familiares, culturales y de integración. 


\section{Referencias bibliográficas:}

Félix Arteaga y Carmen González Enríquez: "La respuesta militar a la crisis migratoria del Mediterráneo", ARI (Real Instituto El Cano) 40/2015, 22.07.2015.

Ziccardi, Giuliana: "The EUNAVFOR MED Operation and the use of force", American Society of International Law, volume 19, issue 27, 18.12.2015. 